\title{
EVOLUCIÓN MORFO-SEDIMENTARIA DEL TRAMO MEDIO DEL RÍO SEGRE
}

\author{
J. TUSET ${ }^{1,2 *}$, D. VERICAT ${ }^{1,2,3}$, R.J. BATALLA $A^{1,2,3,4}$ \\ ${ }^{1}$ Fluvial Dynamics Research Group -RIUS, www.fluvialdynamics.com. \\ ${ }^{2}$ Centre Tecnològic Forestal de Catalunya, E-25280, Solsona. \\ ${ }^{3}$ Departament de Medi Ambient i Ciències del Sòl, Universitat de Lleida, E-25198, Lleida. \\ ${ }^{4}$ Institut Català de Recerca de l'Aigua, E-17003, Girona.
}

RESUMEN. En este trabajo se analiza la evolución hidrológica y morfosedimentaria del tramo medio del río Segre a partir del análisis de la alteración del régimen fluvial y de crecidas y del desequilibrio sedimentario ocurrido durante la segunda mitad del siglo XX. La dinámica del rio se ha visto alterada de manera significativa debido principalmente a la construcción de grandes presas y a la extracción de áridos. El cambio más evidente aguas abajo de la presa de Oliana es el que afecta a la magnitud y frecuencia de las avenidas. Con la construcción de la presa de Rialb este fenómeno se ve incrementado. La retención de sedimentos en los embalses y las numerosas extracciones de áridos han provocado además un notable desequilibrio sedimentario. Se estima que la retención de sedimentos en suspensión oscila entre el 87 y el 96\% (100\% para la carga de fondo). Este importante efecto, unido a una intensa actividad extractiva, que excedió ampliamente la carga media sedimentaria del río, ha incrementado considerablemente el déficit sedimentario del cauce actual y reforzado el desequilibrio hidrodinámico (evidente a partir de las observaciones de acorazamiento e incisión del lecho). La evolución morfológica del río, analizada a partir del Índice de Dinámica Fluvial (IDF), muestra una tendencia a la estabilización del cauce por intrusión de vegetación de ribera posterior al cierre de la presa de Oliana en 1959. Esta tendencia se vio alterada como consecuencia de la gran crecida de 1982, aunque el dinamismo fluvial aparente después de este evento se redujo de nuevo paulatinamente. En la actualidad la movilidad del cauce se ha reducido de manera muy importante y la intrusión de la vegetación de ribera hace que el cauce de aguas bajas tienda a ocupar prácticamente la totalidad del cauce activo. Las principales unidades morfo-sedimentarias (barras laterales y centrales) han desaparecido. Los resultados aportan información para el diseño de programas de restauración hidrosedimentaria que incluyan prácticas tales como las crecidas de mantenimiento y la inyección de gravas. Las crecidas de mantenimiento reactivarían el cauce, y el bypass de sedimentos a través de las presas, reduciría el desequilibrio 
energético y de masas; por su parte, la inyección de gravas minimizaría la incisión y regeneraría hábitats y unidades morfológicas ahora prácticamente desaparecidas.

\section{Morpho-sedimentary evolution of the middle-course reaches of the Segre River}

ABSTRACT. In this study, the hydrological and morpho-sedimentary status of the medium reaches of the River Segre is examined from the analysis of the alteration of the hydrological and floods regime and of the sedimentary imbalance in the second half of the $20^{\text {th }}$ century. In this period, the river has been significantly altered due to the construction of dams and to the inchannel gravel mining. Results show that the alteration of the flow regime downstream from the Oliana Dam is moderate, with the more evident change affecting the magnitude and frequency of floods. The construction of Rialb Dam has magnified channel changes. Sediment retention in reservoirs and the massive in-channel gravel mining have caused a remarkable sedimentary imbalance. The estimated sediment retention is between 87 and 96\% (100\% for bedload). This impact, along with an intense in-channel mining that clearly exceeded the mean sedimentary load of the river, have considerably increased the current sedimentary deficit and reinforced the hydrodynamic imbalance (evident from the observations of armouring and incision in the river bed). The morphological evolution of the river, analysed by means of the Index of Fluvial Dynamism (IFD), shows a tendency towards stabilisation due to the encroachment of riparian vegetation after the closing of the Oliana Dam in 1959. This tendency was temporarily altered by the great flood of 1982. The apparently new fluvial dynamism after this event gradually decreased afterwards. Nowadays, riverbed mobility has definitely decreased and the riparian vegetation encroachment makes the low flow channel to occupy practically all the active river bed. The main morphosedimentary units (lateral and central bars) have disappeared. Results can be used to design hydrosedimentary restoration plans, which include maintenance of artificial floods and gravel injection. Maintenance floods and bypass sediments through reservoirs may reactivate the riverbed, thus reducing the energy and mass imbalances, whereas gravel injections would reduce incision and would re-create habitats and morphological units.

Palabras clave: morfología fluvial, presas, extracción de áridos, $I D F$, Segre.

Key words: channel morphology, dams, construction aggregate, IFD, River Segre.

Recibido el 31 de enero de 2015 Aceptado el 12 de marzo de 2015

*Correspondencia: Centre Tecnològic Forestal de Catalunya, E-25280, Solsona. E-mail: jordi.tuset@ctfc.cat 


\section{Introducción}

Los ríos son sistemas naturales complejos cuya energía se disipa mayoritariamente en forma de trabajo, transfiriendo agua y sedimentos desde las cabeceras hasta las áreas de sedimentación, a la vez que modelan los cauces de la red de drenaje por la que circulan. La interacción entre la dinámica hidrológica y sedimentaria determina no sólo el equilibrio entre los procesos físicos, sino también el estado ecológico del río, y la disponibilidad y características del hábitat fluvial. El transporte de sedimentos desde las cuencas hasta el mar es un proceso fundamental en el proceso de denudación continental. Este proceso ocurre de manera episódica en el tiempo, determinado por los periodos en los que los caudales superan los umbrales de movilidad de los sedimentos (mayoritariamente durante crecidas; i.e. episodios competentes). Generalmente se considera que un tramo de río se encuentra en equilibrio dinámico (o casi-equilibrio) cuando la cantidad de sedimentos erosionada es reemplazada por materiales provenientes de aguas arriba (Schumm, 1977). Cualquier alteración en el régimen de caudales líquido y sólido comporta un cambio de dicho equilibrio y un posterior ajuste de las condiciones morfo-sedimentarias del cauce y de los procesos bio-físicos asociados, incluyendo el hábitat (por ej. Kondolf, 1997). Son numerosos los trabajos en Geomorfología Fluvial que analizan los efectos de diversas actividades antrópicas sobre el régimen de caudales y la carga sólida asociada. En este contexto cabe señalar los efectos de los cambios de los usos del suelo en la cuenca sobre la producción de sedimentos y generación de escorrentía, tal y como indican numerosos trabajos en España en diferentes contextos hidroclimáticos (por ej. Beguería et al., 2006; García-Ruíz, 2010; López-Vicente et al., 2011; Sanchis-Ibor y Segura-Beltrán, 2014). De especial interés además es el estudio de los efectos de la regulación de los caudales por embalses, sobre todo en un contexto climático mediterráneo, donde las presas son un elemento clave en la gestión de los recursos hídricos superficiales.

Las presas reducen la magnitud y frecuencia de las crecidas, y ello comporta ajustes en el balance sedimentario y en la morfología fluvial. Estos cambios afectan (i) la geometría del cauce y la granulometría del lecho, (ii) la movilización de los sedimentos y, consecuentemente, (iii) la formación y renovación de unidades morfológicas como rápidos, pozas, barras, brazos laterales y meandros de gran interés para el hábitat fluvial (por ej. Chien, 1985; Fenner et al., 1985; Copp, 1989; Poff et al., 1997). El grado de alteración de las crecidas depende de las características constructivas y operativas de la presa y de su capacidad de regulación, así como de la forma y los usos particulares de cada embalse. Además de cambiar el régimen de caudales, los embalses también son trampas eficaces de sedimentos. Otro impacto destacado en el medio fluvial es el ocasionado por las extracciones de sedimentos, generalmente con el objetivo de obtener áridos para la construcción. Esta actividad tiene un efecto directo sobre la dinámica morfológica y sedimentaria del río (por ej. Rundquist L.A., 1980; Rivier y Seguier, 1985; Kondolf, 1994a,b; OWRRI, 1995a,b; Kondolf, 1997; Batalla y Vericat, 2011). Las extracciones de áridos comportan cambios en la morfología en planta del río a múltiples escalas temporales. Si la magnitud de estas es considerable, existen numerosos ejemplos en los que el río pasa de una configuración morfo-sedimentaria compleja (por ej. trenzada) a ríos de cauce único y de menor sinuosidad; esta actividad facilita el acorazamiento del lecho y produce incisión y, consecuentemente, elimina además hábitats acuáticos 
y riparios de gran interés (por ej. Piégay et al., 2009; Rinaldi, 2003). El impacto no se limita al tramo original de la extracción sino que los efectos pueden desplazarse aguas arriba y abajo (por ej. Pringle, 1997).

Desde finales de los años 1950, el tramo medio del río Segre (cuenca del Ebro) está sujeto a numerosos impactos antrópicos que han modificado sustancialmente su equilibrio hidrosedimentario. Los impactos más destacados están relacionados con la construcción de embalses y las extracciones de áridos. La primera actividad ha modificado el régimen hidrológico y de crecidas, y ambas han alterado el balance de sedimentos y, consecuentemente, la dinámica morfo-sedimentaria del río. El objetivo de este artículo es analizar la evolución del cauce del río y la respuesta a los impactos ocasionados por la regulación hidrológica y las actividades extractivas. El trabajo presenta de una manera secuencial e integrada diferentes métodos de diagnóstico hidrológico y sedimentario que a menudo se encuentran fragmentados o dispersos, tanto en la literatura científica como en informes técnicos. Este trabajo contribuye así con una propuesta metodológica para la evaluación del estado morfo-sedimentario de tramos fluviales regulados por presas y/o impactados por extracciones de áridos. La premisa básica sobre la que se basa el análisis es el reconocimiento de que el dinamismo de un río y su integridad como ecosistema se fundamenta, entre otros aspectos, en una relación de equilibrio entre el flujo de agua (régimen fluvial e hidráulico), los sedimentos circulantes, y la morfología del cauce.

\section{2. Área de estudio}

La cuenca del río Segre se sitúa en el cuadrante NE de la Península Ibérica, con una superficie de $22845 \mathrm{~km}^{2}$ y una longitud del curso principal de $265 \mathrm{~km}$. El Segre es el principal afluente del Ebro, y, con su cabecera en el Pirineo Oriental, recorre el extremo oriental de la Depresión del Ebro hasta que vierte sus aguas en el embalse de Ribarroja (aguas abajo de la presa de Mequinenza). El clima de la cuenca del Segre es primordialmente de carácter mediterráneo, con rasgos alpinos en la cabecera y tendencia a la continentalidad en su tramo final. La precipitación y la temperatura media anual de la cuenca son $576 \mathrm{~mm} \mathrm{y} 12^{\circ} \mathrm{C}$, respectivamente. En la cabecera del curso principal y en sus principales afluentes (i.e. el Cinca, las Nogueras) predominan los materiales silíceos, de carácter ácido y de baja solubilidad, alternados, aguas abajo, con franjas de naturaleza calcárea. Ya en la depresión y hasta su desembocadura, el río circula sobre materiales sedimentarios (conglomerados, areniscas, lutitas y, esporádicamente, yesos). El río tiene un régimen hidrológico de tipo nivo-pluvial. Durante el invierno la pluviometría es escasa y la mayor parte de la precipitación se concentra en la montaña y se produce en forma de nieve. En primavera las lluvias son más abundantes y, junto con el deshielo, hacen que los caudales del río alcancen los valores máximos anuales. El mínimo anual se produce en verano. El caudal medio diario $\left(\mathrm{Q}_{\mathrm{n}}\right)$ en la parte baja de la cuenca es de $86 \mathrm{~m}^{3}$ $\mathrm{s}^{-1}$ (en Seròs, última estación de aforo antes de la confluencia con el Cinca y el Ebro). Los caudales máximos $\left(\mathrm{Q}_{\mathrm{ci}}\right)$ estimados durante el siglo XX en Lleida se registraron en otoño, alcanzando $5200 \mathrm{~m}^{3} \mathrm{~s}^{-1}$ en 1907 y $3600 \mathrm{~m}^{3} \mathrm{~s}^{-1}$ en 1937 y 1982 (Balasch et al., 2006). El índice de torrencialidad (expresado como $\mathrm{Q}_{\mathrm{ci}} / \mathrm{Q}_{\mathrm{n}}$ ) es de 60 . 
El tramo de estudio seleccionado se considera representativo del Segre medio (40 km, Fig. 1) y queda delimitado por los municipios de Ponts (aguas abajo de la presa de Rialb) y Alòs de Balaguer (aguas arriba de la confluencia con uno de sus principales tributarios, el Noguera Pallaresa). Desde finales de los años 1950 el tramo medio del río Segre ha experimentado una notable alteración de su dinámica fluvial debido a diversas actividades antrópicas. Las presas de Oliana (construida en 1959) y Rialb (1998), con una capacidad de 101 y de $403 \mathrm{hm}^{3}$ respectivamente, han alterado el régimen natural de caudales líquido (habituales y de crecida) y sólido del río. Asimismo, desde los años 1970, el desequilibrio sedimentario se ha visto incrementado por continuadas extracciones de áridos a lo largo del tramo de estudio.

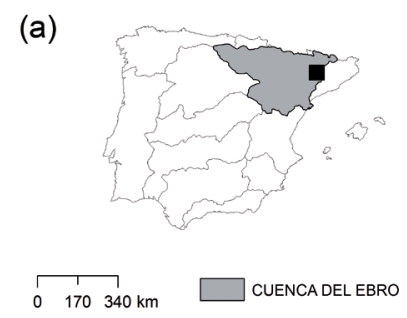

(b)

(b)

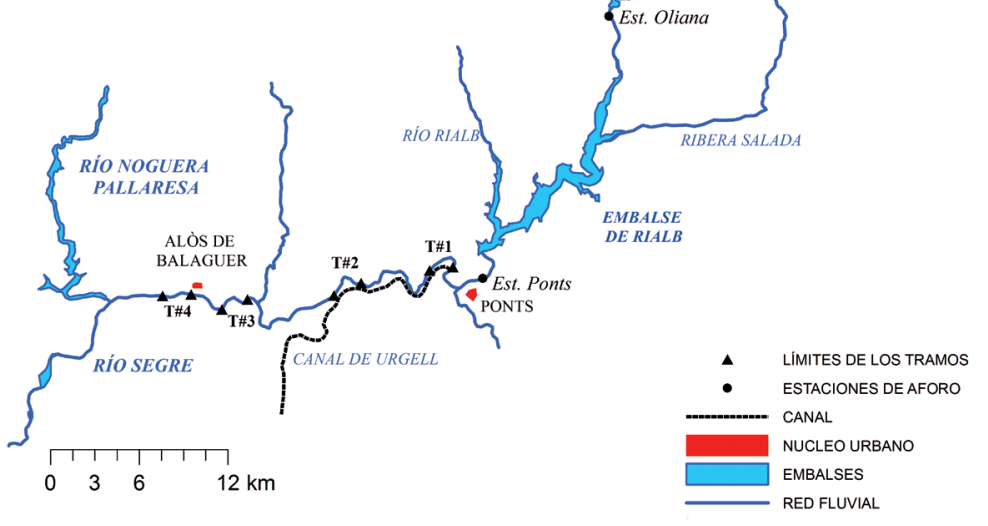

Figura 1. (a) Localización de la cuenca del Segre en la Península Ibérica. (b) Localización del área de estudio con indicación de los 4 sub-tramos analizados del sector medio del río Segre.

\section{Metodología}

El estudio analiza la evolución morfológica del tramo medio del Segre en relación con el régimen de crecidas y la disponibilidad de sedimentos, haciendo hincapié en la respuesta del sistema fluvial a los desajustes de origen antrópico (por ej. presas y actividades extractivas). Para ello, se ha seguido una metodología integrada y secuencial sobre la base de cuatro criterios de evaluación y estructurada en cinco bloques (Fig. 2). Los dos primeros bloques metodológicos están relacionados con el análisis del impacto y se centran en la cuantificación de las entradas de energía (caudales) y de la disponibilidad de 
sedimentos que el sistema tiene para mantener su equilibrio morfológico y sedimentario: 1) caracterización de caudales habituales y de crecida y 2) cambios en el balance de sedimentos. El tercer bloque (evolución morfológica) analiza la respuesta del sistema fluvial en relación con los cambios de las cargas líquida y sólida, y la reducción de las áreas fuente de sedimento en el propio cauce. El bloque cuatro está relacionado con el análisis morfo-sedimentario actual y se centra en la modelización hidráulica y de inicio de movimiento de las partículas del lecho (i.e. competencia del flujo) durante escenarios de crecida actuales. El último bloque (5, integración de resultados) evalúa la relación causa-efecto mediante el análisis de la influencia de los cambios en el balance de agua y de sedimentos en la evolución morfológica, y plantea algunas propuestas de mejora de acuerdo con el diagnóstico y con la respuesta observada del sistema. A continuación se describen detalladamente cada uno de los bloques metodológicos.

CRITÉRIOS DE EVALUACIÓN

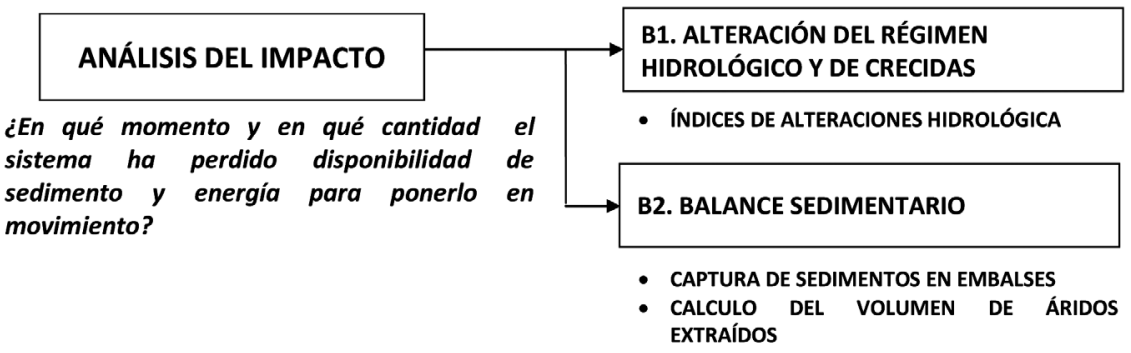

\section{BLOQUES}

SENSIBILIDAD

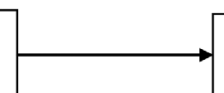

B3. EVOLUCIÓN MORFOLÓGICA

- cReación de una base de dATOS CARTOGRÁFICA DE LAS UNIDADES SEDIMENTARIAS

B4.MODELIZACIÓN HIDRÁULICA DE LAS CONDICIONES HIDRO-SEDIMENTARIAS

- INFORMACIÓN DE CAMPo

- MODElizaCIón

¿Cuál es la dinámica morfo-sedimentaria actual y que potencial de recuperación ofrece al río?

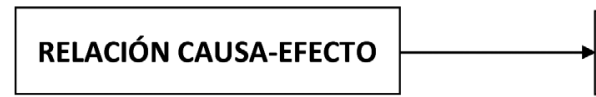

B5. INTEGRACIÓN DE RESULTADOS

¿Cuál es la contribución de los agentes antrópicos sobre la respuesta del sistema

- ANÁLISIS ESTADISTICO morfo-sedimentario?

- DIAGNOSTICO Y PROPUESTAS DE MEJORA

Figura 2. Esquema metodológico para el diagnóstico de la dinámica morfo-sedimentaria del tramo medio del río Segre: Interrelación entre criterios de evaluación y bloques de análisis de datos. 


\subsection{Régimen hidrológico y de crecidas}

La metodología empleada para la caracterización del estado hidrológico se ha hecho de acuerdo con los trabajos de Batalla et al. (2004) y Martínez-Santa y Fernández-Yuste (2006). A partir de estas referencias presentamos un conjunto de índices denominados de Alteración Hidrológica (IAH) que permiten evaluar de manera cuantitativa los cambios en el régimen de caudales, sobre todo de aquellos con más interés geomorfológico debido a su competencia, los caudales de crecida.

La caracterización hidrológica se estructura en dos bloques. El primer bloque analiza el régimen natural de caudales (RNC) y el segundo el régimen modificado de caudales (RMC). El análisis del RNC se efectúa a partir de los caudales anuales, mensuales y diarios medios de las estaciones de Organyà (único punto de control libre de regulación), Oliana y Ponts (Fig. 1; Tabla 1) con el objetivo de determinar las características del régimen hidrológico natural.

Tabla 1. Registros de datos de las estaciones de aforo en el tramo medio del Segre. Fuente: Confederación Hidrográfica del Ebro.

\begin{tabular}{|l|c|c|c|}
\hline Estación $^{\mathbf{1}}$ & Inicio Serie & Duración de la serie & Años completos \\
\hline Organyà & 1950 & 55 & 51 \\
\hline Oliana & 1952 & 57 & 50 \\
\hline Ponts $^{2}$ & 1946 & 68 & 45 \\
\hline
\end{tabular}

${ }^{1}$ Los datos de caudal plantean en ocasiones problemas de homogeneidad de las series ya que las estaciones de aforo sufren cambios a lo largo de su historia (por ej. cambios en la colocación de la escala, cambios ubicación, etc.). El Servicio de Hidrometría de la CHE es el organismo encargado de la supervisión de estos aspectos (realizando anualmente una media de 1300 aforos directos para ir ajustando las curvas de gasto de las 223 estaciones de aforo). En este trabajo hemos tomado como correctos los datos suministrados una vez estos han sido validados por sus técnicos. En algunas ocasiones cuando una de las estaciones queda afectada por una crecida, deja incluso de estar en servicio durante un tiempo hasta que se ha reconstruido y recalibrado. El análisis detallado de la historia de cada una de las estaciones queda fuera del alcance este trabajo.

${ }^{2}$ Serie hidrológica de Ponts (1946-1982) completada con los registros de salida del embalse de Rialb (2000-2014).

El régimen modificado de caudales (RMC) se analiza a partir de i) el régimen modificado de los caudales habituales ( $\mathrm{RMC}_{\mathrm{Hb}}$, entendidos como caudales no extremos) $\mathrm{y}$ ii) el régimen modificado de crecidas $\left(\mathrm{RMC}_{\mathrm{Cd}}\right)$. Al mismo tiempo, se ha calculado el Índice de Regulación (IR, de Batalla et al., 2004) de la cuenca. Este índice se toma como indicador de la capacidad de alteración hidrológica de los embalses sobre el RNC. El IR es el cociente entre la capacidad del embalse y la aportación media anual, expresado como un valor adimensional, pero asimilables al tiempo de residencia del agua en el embalse. Para evaluar los regímenes de caudales modificados (i.e. $\mathrm{RMC}_{\mathrm{Hb}}$ y $\mathrm{RMC}_{\mathrm{Cd}}$ ) se identificaron dos puntos de control foronómicos para cada uno de los embalses, uno ubicado aguas arriba y otro aguas abajo. Se han seleccionado estaciones con una 
disponibilidad de datos similar. En el caso del $\mathrm{RMC}_{\mathrm{Hb}}$, los parámetros analizados (ver Tabla 2) son la magnitud anual de la escorrentía, la estacionalidad y la variabilidad diaria (Martínez-Santa y Fernández-Yuste, 2006, a partir de Puckridge et al., 1998; Growns y Marsh, 2000). Adicionalmente, también se ha añadido la variabilidad mensual de la escorrentía siguiendo la metodología de Batalla et al., (2004). Las variables analizadas para el estudio del $\mathrm{RMC}_{\mathrm{Cd}}$ son la magnitud y frecuencia, la variabilidad, la estacionalidad y la duración de las crecidas. El estudio de la magnitud y frecuencia se realiza a partir de i) la media de los máximos caudales diarios anuales $\left(\overline{Q_{C}}\right)$ y, si se dispone, de la media de los caudales máximos instantáneos anuales $\left(\overline{\mathrm{Q}_{\mathrm{Ci}}}\right)$, ii) el caudal bankfull $\left(\mathrm{Q}_{\mathrm{Bank}}\right) \mathrm{y}$, iii) el caudal máximo ordinario o caudal de crecida $\left(\mathrm{Q}_{5}\right)$ correspondiente al percentil 5 (por ej. Clausen y Biggs, 2000; Baker et al., 2004; Batalla et al., 2004), tomado de una curva de caudales clasificados. Para el cálculo del caudal bankfull $\left(\mathrm{Q}_{\mathrm{Bank}}\right)$ se ha seguido el cálculo propuesto por Villarroya y Xuclá (2003):

$$
\mathrm{Q}_{\mathrm{Bank}}=\left(\overline{\mathrm{Q}_{\mathrm{C}}}\right) \times\left(0,7+0,6 \times \mathrm{CV}_{\mathrm{Qc}}\right)
$$

donde

$\mathrm{Q}_{\text {Bank }}$ es el caudal bankfull, de cauce lleno o formativo, en $\mathrm{m}^{3} \mathrm{~s}^{-1},\left(\overline{\mathrm{Q}_{\mathrm{C}}}\right)$ es la media de la serie de caudales máximos medios diarios anuales $\left(\mathrm{m}^{3} \mathrm{~s}^{-1}\right)$ y $\mathrm{CV}_{\mathrm{Qc}}$ es el coeficiente de variación de la serie de máximos caudales medios diarios anuales.

Tabla 2. Aspectos del régimen natural (RNC) y modificado (RMC) analizados.

\begin{tabular}{|c|c|c|}
\hline VALORES & ASPECTO & PARÁMETROS \\
\hline \multirow{3}{*}{$\begin{array}{l}\text { Anuales y } \\
\text { mensuales }\end{array}$} & Magnitud & Media de las aportaciones anuales \\
\hline & Variabilidad & $\begin{array}{l}\text { Diferencia entre la aportación mensual máxima y mínima en el } \\
\text { año }\end{array}$ \\
\hline & Estacionalidad & Mes de máxima y mínima aportación del año \\
\hline Diarios & Variabilidad & $\begin{array}{l}\text { Diferencia entre los caudales medios correspondientes a los } \\
\text { percentiles de excedencia del } 10 \% \text { y } 90 \%\end{array}$ \\
\hline \multirow[t]{4}{*}{$\begin{array}{l}\text { Crecidas } \\
\text { (Extremos) }\end{array}$} & $\begin{array}{l}\text { Magnitud } \\
\text { y frecuencia }\end{array}$ & $\begin{array}{l}\text { Media de los máximos caudales diarios anuales }\left(\overline{Q_{C}}\right) \\
\text { Caudal formativo o bankfull }\left(\mathrm{Q}_{\text {Bank }}\right) \\
\text { Caudal de la avenida habitual }\left(\mathrm{Q}_{5}\right)\end{array}$ \\
\hline & Variabilidad & $\begin{array}{l}\text { Coeficiente de variación de caudales máximos anuales diarios } \\
\left(\mathrm{CV}_{\mathrm{Qc}}\right) \\
\text { Coeficiente de variación de la serie de avenidas habituales }\left(\mathrm{CV}_{\mathrm{Q} 5}\right)\end{array}$ \\
\hline & Estacionalidad & $\begin{array}{l}\text { Máximo número de días consecutivos con un caudal medio } \\
\text { diario }>\mathrm{Q}_{5}\end{array}$ \\
\hline & Duración & Máximo número de días consecutivos al año con $\mathrm{Q}>\mathrm{Q}_{5}$ \\
\hline
\end{tabular}


Para el estudio de la variabilidad, tanto para las variables que se incluyen en el RNC y en el RMC, se ha utilizado el coeficiente de variación de los $\mathrm{Q}_{\mathrm{c}} \mathrm{y}$ el de los $\mathrm{Q}_{5}$. Finalmente, para la estacionalidad y la duración se han tomado el número de días al mes con caudales medios diarios superiores al $\mathrm{Q}_{5}$ y el máximo número de días consecutivos con un caudal medio diario superior al $\mathrm{Q}_{5}$, respectivamente (Martínez-Santa y FernándezYuste, 2006; ver Tabla 2). Una vez calculados los parámetros indicados y su variabilidad tanto para el régimen natural de crecidas $(\mathrm{RNC})$ como para el modificado $\left(\mathrm{RMC}_{\mathrm{Cd}}\right)$, se ha evaluado la distorsión originada calculando el cociente entre ellos. Estos cocientes representan los Índices de Alteración Hidrológica (IAH). A continuación se describen los distintos niveles de perturbación en función a la magnitud de estos.

Con el objetivo de ofrecer una valoración no sólo cuantitativa sino también cualitativa del grado de alteración hidrológica del río, se proponen cinco estados hidrológicos, definidos según las recomendaciones de la EU Common Implementation Strategy (Communities European, 2003) para la Directiva Marco del Agua en su epígrafe 2.6 sobre la clasificación del estado ecológico a partir de las Ecological Quality Ratios. Estas ratios atribuyen a cada parámetro del régimen hidrológico analizado un estado de alteración determinado en función del resultado de los IAH. Los criterios de representación y asignación de cada nivel de perturbación son: Bajo $0,80<\mathrm{IAH} \leq 1$; Moderado $0,60<\mathrm{IAH} \leq 0,80$; Importante $0,40<\mathrm{IAH} \leq 0,60$; Severo 0,20<IAH $\leq 0,40$; Muy Severo $0 \leq \mathrm{IAH} \leq 0,20$.

La integración de las variables alteradas en un solo análisis se obtiene a partir del Índice de Alteración Global (IAG). La alteración global se presenta en un gráfico que integra todos los índices en un plano con tantos ejes como índices haya, un heptágono en este caso. La línea que une los extremos exteriores del heptágono, con un valor de 1, muestra el estado RNC (i.e. régimen natural). Un segundo heptágono, situado en el interior del que representa el RNC, cruza cada eje a una distancia del centro proporcional al valor de cada índice. Este segundo heptágono representa el régimen modificado (i.e. RMC). Si el valor de un índice para RNC coincide con el obtenido para el RMC, ambos heptágonos comparten el vértice que conforma dicho índice. Por el contrario, los vértices de los heptágonos difieren a medida que las diferencias entre los índices aumentan. Finalmente, el IAG se calcula como el cociente entre el área definida por el polígono de RNC y el área de RMC (el gráfico del IAG se muestra en la Fig. 3 en la sección de resultados):

$$
I A G=\frac{{ }^{\mathrm{s}} \mathrm{RMC}}{{ }^{\mathrm{s}} \mathrm{RNC}}=\frac{\sum_{\mathrm{i}}^{\mathrm{n}}=1 \frac{1}{2} \mathrm{a}_{\mathrm{i}} \mathrm{a}_{\mathrm{i}}+1 \operatorname{sen} \frac{2 \Pi}{\mathrm{n}}}{\mathrm{n}\left[\frac{1}{2} \operatorname{sen} \frac{2 \Pi}{\mathrm{n}}\right\rceil}=\ldots=\frac{\left(\sum_{\mathrm{i}}^{\mathrm{n}}=1 \mathrm{a}_{\mathrm{i}}\right)^{2}-1 \sum_{\mathrm{i}}^{\mathrm{n}}=1 \mathrm{a}_{1}^{2}}{\mathrm{~m}(\mathrm{~m}-1)}
$$

donde $\mathrm{S}_{\mathrm{RMC}}$ es la superficie definida por el polígono en $\mathrm{RMC}, \mathrm{S}_{\mathrm{RNC}}$ la superficie definida por el polígono en $\mathrm{RNC}, \mathrm{a}_{\mathrm{i}}$ el valor resultante que toma cada índice de alteración parcial y m el número de índices que evalúan cada aspecto del régimen de caudales (en este caso siete).

Respecto a los Índices de Alteración Global (IAG) se obtienen los criterios de representación y asignación del estado de alteración hidrológica: Bajo $0,64<\mathrm{IAG} \leq 1$; Moderado 0,32<IAG $\leq 0,64$; Importante 0,16<IAG $\leq 0,32$; Severo 0,04<IAG $\leq 0,16$; Muy

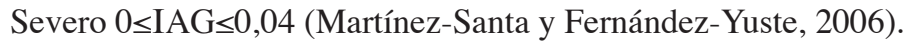


a)

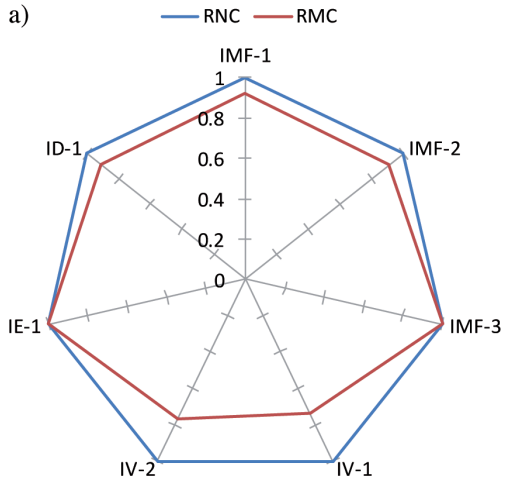

b)

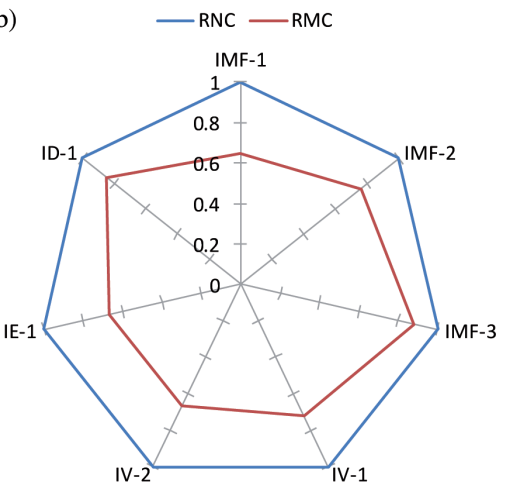

Figura 3. Índices de alteración hidrológica (IAH). Valoración de la alteración de los caudales máximos de crecida correspondientes al análisis de los efectos aguas abajo del embalse de a) Oliana y b) Rialb. Cada índice se identifica con un código. Para más detalles ver la sección 4.1.3 y la tabla 5 del artículo. También se observa el estado de alteración global (IAG) mediante la comparación de la superficie definida por el RNC (línea azul) con los índices parciales de alteración hidrológica (línea roja).

Finalmente, y aún dentro del apartado hidrológico, se analiza la magnitud (i.e. pico de caudal) de las crecidas de 50 años de período de retorno $\left(\mathrm{T}_{50}\right.$; periodo similar a la longitud de las series) y los hidrogramas de crecida disponibles aguas arriba y abajo de los embalses. Para el primer análisis se ha empleado la distribución de valores extremos de Gumbel (tipo 1) ajustando los valores de $\mathrm{Q}_{\mathrm{c}} \mathrm{y} \mathrm{Q}_{\mathrm{ci}}$ en las estaciones de Organyà y de Oliana (embalse de Oliana), y los valores de $\mathrm{Q}_{\mathrm{c}}$ en la estación de Oliana y en salida del embalse de Rialb. El segundo análisis tiene interés por la importancia de las crecidas como principal factor generador de procesos morfo-sedimentarios. Para ello se han examinado parejas de hidrogramas, registrados aguas arriba y abajo de los embalses de Oliana y de Rialb. Los hidrogramas se han clasificado en dos grupos en función de su efecto potencial sobre la dinámica morfológica y sedimentaria del río. Por un lado, se han seleccionado i) las crecidas ordinarias con caudales superiores al $\mathrm{Q}_{5}$ en la curva de caudales clasificados $y$, por otro, ii) se han tomado las crecidas extraordinarias, consideradas aquellas con caudales superiores al caudal bankfull y con periodos de retorno superior a 2 años i.e. $\mathrm{T}_{\mathrm{x}}>\mathrm{T}_{2}$ años, donde $x$ es el período en años). El análisis se ha llevado a cabo a partir de los datos quinceminutales de caudal disponibles en las estaciones de Organyà y Oliana desde 1997, y también desde 2004 a la salida de la presa de Rialb. En el caso de la crecida extraordinaria de noviembre de 1982 tan solo se dispone de datos de caudal con una frecuencia horaria (Puigdefàbregas, 1984).

\subsection{Balance de sedimentos}

La retención de sedimentos en diques y presas se utiliza ampliamente como estimación global de la producción de sedimentos de una cuenca (por ej. Batalla y Vericat 2011; Díaz et al., 2014; Molina-Navarro et al., 2014). En el caso del río Segre, 
la retención en los embalses se ha estimado inicialmente a partir de la curva de Brune (1953) (en Oliana y Rialb), y también comparando las batimetrías disponibles (Oliana). La curva de Brune estima la tasa de retención de un embalse a partir de su capacidad y de la aportación hídrica anual afluente. La estimación es aplicable al sedimento en suspensión, que es la parte de la carga sólida que habitualmente representa la mayoría del transporte en medios aluviales y que es susceptible (en parte) de franquear la presa. En cambio, la retención de sedimentos derivada de batimetrías representa la totalidad de la carga sedimentaria (material fino en suspensión y grueso como carga de fondo).

El volumen de sedimentos extraídos para áridos de construcción en el tramo medio del Segre y su distribución temporal se ha cuantificado a partir del registro de licencias (agrupadas mediante la base municipal) de la Confederación Hidrográfica del Ebro (CHE, 1973-2009). Para ello se ha considerado que el volumen de concesión coincide con el volumen extraído y que la extracción se ha efectuado el mismo año de la concesión. Con esta información se ha calculado el volumen extraído para todo el período y también para cada uno de los períodos analizados en el estudio morfo-sedimentario, tanto para todo el tramo de estudio como en cada uno de los municipios por los que circula el río.

\subsection{Evolución morfológica}

El estudio evolutivo del cauce del medio del Segre se ha realizado a partir de las fotografías aéreas históricas, y de ortofotos actuales. La elección de las fotografías aéreas se halla determinada por el número de periodos de análisis y por su disponibilidad. En el caso de que se disponga de más de una serie fotográfica para cada uno de los periodos considerados se ha tenido en cuenta: (a) el régimen de crecidas, (b) la calidad de las fotografías, (c) la tipología (blanco y negro, color) y (d) el formato en el que se pueden adquirir (papel o digital). Una vez seleccionadas las fotografías aéreas (contactos) se han escaneado en alta resolución (600 dpi) para su geo-referenciación y análisis. La geo-referenciación se ha realizado mediante la extensión Georeferencing de ArcMap 9.3 ${ }^{\circledR}$. La corrección de las imágenes se ha llevado a cabo utilizando puntos de control (GCP) de fácil identificación en las fotografías, extraídos del ortofotomapa del año 2008 (Fuente: Institut Cartogràfic de Catalunya) con una resolución de $5 \mathrm{~m}$. El número de GCP oscila entre 22 y 87 por fotograma. Para la transformación se han utilizado métodos de transformación no polinomiales del tipo Spline y Adjust. La calidad de la transformación se ha evaluado mediante el Error Medio Cuadrático (EMQ) de los residuales de cada una de las coordenadas de los GCPs.

Una vez geo-referenciadas, las imágenes se han utilizado para la identificación visual de unidades morfológicas. Los criterios para la identificación son forma, tamaño, estructura, textura, tonalidad y colores. Una vez identificadas las unidades, se han cartografiado en planta con el objetivo de delimitarlas, calcular su extensión, y crear una base de datos cartográfica digital y geo-referenciada. La cartografía se ha realizado a partir de una escala de trabajo única (1:5000) para todos los contornos. Cada una de las unidades se ha clasificado de acuerdo con la tipología definida por Campy y Macaire (1989) y teniendo en cuenta los objetivos específicos del trabajo y la calidad de la información de base. La tabla 3 presenta la descripción y nomenclatura de las unidades morfológicas utilizadas durante la identificación e interpretación visual. La cartografía de la morfología fluvial durante diferentes periodos 
temporales de un mismo tramo permite el análisis de su evolución. Para ello, se parte de la serie fotográfica de 1956 como base para la identificación de unidades morfológicas en un contexto considerado de mínimo impacto. El límite del área cartografiada es la envolvente del área activa del lecho en las fotografías aéreas de ese año. La subsiguiente identificación de las unidades morfológicas para cada periodo se realiza dentro de dichos límites. Tanto la cartografía como el análisis temporal posterior se ha realizado con ArcMap 9.3 ${ }^{\circledR}$. La extensión del área cartografiada de las unidades y todos los cálculos que se derivan están influenciados por las condiciones de caudal en el momento de la obtención de las fotografías, pudiendo obtener resultados erróneos al comparar la cartografía de periodos donde el caudal circulante es significativamente diferente. Para identificar si había diferencias significativas se compararon los caudales medios diarios registrados el mismo día del vuelo de la toma de las fotografías aéreas. En todos los casos, las fotografías se obtuvieron en época de aguas bajas, con caudales inferiores al nivel bankfull (i.e. entre el 10 y el $32 \%$ ).

Tabla 3. Tipología y descripción de las unidades morfológicas utilizadas en el proceso de interpretación visual de las fotografías aéreas.

\begin{tabular}{|l|l|l|}
\hline CÓDIGO & NOMENCLATURA & \multicolumn{1}{c|}{ DESCRIPCIÓN } \\
\hline CAB & Cauce de Aguas Bajas & $\begin{array}{l}\text { Unidad que delimita el cauce de aguas bajas, el área } \\
\text { ocupada por el agua en condiciones de caudal medio. }\end{array}$ \\
\hline BCA & Barra Central Activa & $\begin{array}{l}\text { Barras (i.e. depósito sedimentario en condiciones de caudal } \\
\text { medio) situadas en el centro del cauce, rodeadas de dos Cau- } \\
\text { ces Activos y con presencia de sedimentos y poca vegetación. } \\
\text { Se caracterizan por la presencia de materiales móviles duran- } \\
\text { te crecidas frecuentes y de magnitud moderada. }\end{array}$ \\
\hline BCV & Barra Central Vegetada & $\begin{array}{l}\text { Barras centrales sin actividad sedimentaria, y colonizadas } \\
\text { por la vegetación. }\end{array}$ \\
\hline BLA & Barra Lateral Activa & $\begin{array}{l}\text { Barras actualmente activas situadas en uno de los márge- } \\
\text { nes del cauce. Tan sólo hay un cauce activo en situación } \\
\text { caudal medio. Estas barras pueden pasar a ser centrales en } \\
\text { situaciones de crecida. }\end{array}$ \\
\hline CA & Cauce Activo & $\begin{array}{l}\text { Superficie que queda inundada en caudales de recurrencia } \\
\text { frecuentes pero no extremos. De manera general se puede } \\
\text { decir que coincide en el caudal asociado a niveles de cauce } \\
\text { lleno (i.e. bankfull). Superficie que incluye el (los) cauce } \\
\text { (es) de aguas bajas y las barras activas. }\end{array}$ \\
\hline CUL & Cultivos & $\begin{array}{l}\text { Parte del cauce ocupada por cultivos sin modificar su } \\
\text { forma básica. Esta perturbación (impacto) reduce el área } \\
\text { activa previa a la ocupación. }\end{array}$ \\
\hline
\end{tabular}

El área analizada en 1956 se tomó como la superficie total sobre la que se estudió la evolución de las unidades morfológicas del cauce (con una superficie total de 5,7 km²). Posteriormente, los cambios generados por la crecida de 1982 (crecida extraordinaria) obligaron a ampliar el área de análisis hasta una superficie de $7 \mathrm{~km}^{2}$. Los cinco periodos de análisis son 1956-1975, 1975-1982, 1982-1992, 1992-1999 y 1999-2008. 


\subsection{Modelización hidráulica y análisis de competencia del régimen de caudales}

El objetivo de este bloque metodológico es examinar la dinámica actual del tramo medio del Segre en función de la competencia de las crecidas liberadas desde la presa de Rialb. Debido a la heterogeneidad del tramo se han identificado 4 sub-tramos (de una longitud de $3 \mathrm{~km}$ los tres primeros y $1 \mathrm{~km}$ el último) correspondientes a distintos patrones morfo-sedimentarios (Fig. 1). Los sub-tramos se sitúan entre la toma del Canal d'Urgell y Alòs de Balaguer (Fig. 1). En cada uno de estos tramos se ha seleccionado una sección representativa de las características geomorfológicas observadas, y en ella se ha obtenido información de campo (topografía, granulometría, nivel máximo inundado reciente) para modelizar los diferentes caudales de crecida. El muestreo del material superficial consistió en la realización de transectos lineales siguiendo el método de contaje o de Wolman (Wolman, 1954; Church et al., 1987). En cada una de las secciones se midió el eje $b$ de un mínimo de 100 partículas (453 en total). Asimismo, en cada sección se tomaron fotografías en planta cercanas al lecho del río (ca. 1 metro) para determinar, de manera complementaria al contaje, la granulometría del material superficial. Estas fotografías se trataron con el software Digital Gravelometer ${ }^{\circledR}$ para modificar su proyección, identificar granos y elaborar las correspondientes distribuciones granulométricas (Graham et al., 2005; LUEL, 2005). La modelización hidráulica permite obtener los datos necesarios para estimar el inicio de movimiento de las fracciones características de la distribución granulométrica en las secciones de control y determinar así la competencia de los caudales. Adicionalmente, se ha determinado el caudal bankfull a partir de un método hidráulico (i.e. cálculo a partir del caudal medio capaz de rellenar el cauce principal en cada tramo de estudio) y su competencia (i.e. extraída a partir de la modelización hidráulica de este caudal). La modelización se ha realizado mediante HEC-RAS ${ }^{\circledR}$ V.4.1. (USACE, 2010). Se trata de un programa de cálculo de flujo hidráulico unidimensional en lámina libre. La determinación de los coeficientes de rugosidad se ha realizado a partir de la clasificación del material del lecho y de las características de los márgenes de acuerdo con a las observaciones de campo. La caracterización relativa a las zonas adyacentes al cauce, se ha completado con el mapa de coberturas vegetales y usos del suelo de Cataluña del año 2002 (DMAH, 2004) y con la información visual obtenida de las ortofotos 1:2500 (año 2009). El cálculo de la rugosidad (n) del cauce activo se ha realizado siguiendo la aproximación de Manning-Strickler (Manning, 1891; Strickler, 1923):

$$
\mathrm{n}=0,015\left(\mathrm{D}_{50-\mathrm{s}}\right)^{1 / 6}
$$

donde el $\mathrm{D}_{50 \text {-s }}$ corresponde al percentil 50 (en metros) de la distribución granulométrica superficial. Los valores de rugosidad asociados a las diferentes coberturas vegetales o usos del suelo se han extraído a partir de tablas de referencia disponibles en manuales de hidráulica (por ej. Martín Vide, 2002). El cálculo de los caudales críticos para el inicio de movimiento del material del lecho se ha realizado teniendo en cuenta el efecto de protección superficial (hiding). Este fenómeno afecta a las condiciones de inicio de movimiento de las fracciones granulométricas más pequeñas. Estas partículas tienden a un no-movimiento (estabilidad) bajo tensiones de corte teóricas superiores a los valores teóricos de inicio de movimiento (Egiazaroff, 1965). De la misma forma, las partículas 
con mayor exposición al flujo, de mayor tamaño, pueden ser movilizadas con tensiones inferiores a las teóricas de inicio de movimiento. Los cálculos de la competencia del flujo se han realizado a partir de las siguientes ecuaciones:

$$
\begin{aligned}
& \tau=\text { D.g.S. } \rho \\
& \tau_{c-D i}=\left[\tau \cdot g \cdot D_{i} \cdot\left(\rho_{s}-\rho\right)\right] \cdot \varepsilon_{i} \\
& \varepsilon_{i}=0,4 \cdot\left(D_{i} / D_{u}\right)^{-0,5}+0,6 \\
& D u=1,6 \cdot D_{50-S}\left(D_{84-s} / D_{16-s}\right)^{-0,28}
\end{aligned}
$$

donde $\mathrm{D}_{\mathrm{i}}$ es el diámetro de la partícula $(\mathrm{m})$ del percentil y correspondiente de la distribución granulométrica superficial, $\mathrm{D}_{u}$ es un factor de dispersión granulométrica que determina la rugosidad del cauce (White y Day, 1982), d es la profundidad del agua (en $\mathrm{m})$, $\varrho$ es la densidad del agua $\left(1000 \mathrm{~kg} \mathrm{~m}^{-3}\right), \varrho_{\mathrm{s}}$ es la densidad específica del sedimento $\left(2650 \mathrm{~kg} \mathrm{~m}^{-3}\right)$, g es la constante gravitacional $\left(9.81 \mathrm{~m} \mathrm{~s}^{-2}\right), \mathrm{S}$ es la pendiente $\left(\mathrm{m} \mathrm{m}^{-1}\right), \varepsilon_{\mathrm{i}-\mathrm{s}}$ la función de protección atribuida a una partícula $\mathrm{D}_{\mathrm{i}}, \mathrm{y}_{16-\mathrm{s}}, \mathrm{D}_{50-\mathrm{s}} \mathrm{D}_{84-\mathrm{s}}$ son los percentiles respectivos $(\mathrm{m})$ de la distribución granulométrica superficial, $\tau$ es la tensión que ejerce el agua $\left(\mathrm{N} \mathrm{m}^{-2}\right), \tau_{c-D i}$ es la tensión de corte crítica $\left(\mathrm{N} \mathrm{m}^{-2}\right)$ para la movilización de una partícula de material superficial de tamaño $\mathrm{D}_{\mathrm{i}}, \mathrm{y} \tau^{*}$ es la tensión crítica adimensional de Shields (0.045) cuando $\mathrm{D}_{\mathrm{i}}$ del material superficial es $\mathrm{D}_{50-\mathrm{s}} \mathrm{y}$ el resto de tamaños se mueven en un estrecho rango de $\tau^{*}$ (según Church, 2006). El valor de $\varepsilon_{\mathrm{i} \text { s }}$ se utiliza como multiplicador de la tensión critica de inicio de movimiento, lo que reduce o incrementa el valor teórico crítico a un valor considerado como efectivo según Sutherland (1992).

Cuando el material del lecho está expuesto a caudales no competentes para la movilización de todas las fracciones que lo componen, el material superficial aumenta progresivamente de tamaño debido a este transporte selectivo $\mathrm{y}$, consecuentemente, se incrementa la diferencia respecto al material subyacente. Esta hipótesis se puede verificar mediante el índice de acorazamiento $\left(\mathrm{I}_{\mathrm{a}}\right)$, calculado como el cociente entre el $\mathrm{D}_{50-\mathrm{s}}$ y el $\mathrm{D}_{50 \text {-ss }}$ (Bunte y Abt, 2001). El coeficiente de acorazamiento presenta valores próximos a 1 en ríos donde no existe una diferencia substancial entre los materiales superficiales y subsuperficiales. En cambio, en ríos o periodos en los que los caudales no son competentes para transportar todas las fracciones del lecho, la movilización es de tipo selectivo (i.e. movilización frecuente de las más pequeñas y largos tiempos de residencia de las más gruesas), hecho que provoca un desequilibrio progresivo entre el suministro de sedimentos y la capacidad de transporte del flujo; en estos cauces el acorazamiento es más elevado y, normalmente, se sitúa en valores de I $>2$ (Bunte y Abt, 2001).

\subsection{Análisis estadístico: integración de resultados}

El objetivo del análisis estadístico es examinar cuál es el peso de cada una de las alteraciones descritas en los bloques relacionados con el análisis de impacto y de sensibilidad (bloques 1, 2 y 3). Para ello se ha efectuado un análisis multivariante mediante el paquete informático Statistica $7.0^{\circledR}$. La regresión lineal múltiple permite analizar la relación entre una variable dependiente y un conjunto de variables independientes (i.e. 
el peso de cada variable en el conjunto de la relación). En este estudio se han hecho diferentes análisis tomado como variables dependientes los parámetros morfológicos del cauce identificados en la tabla 3 (i.e. superficie de aguas bajas, superficie del cauce activo, superficie de barras activas de todo el tramo). Las variables independientes seleccionadas han sido: i) el $\mathrm{Q}_{\mathrm{ci}}$ máximo de cada intervalo analizado como parámetro hidrológico, ii) la extracción media anual de áridos como parámetro morfo-sedimentario, y iii) la retención anual media de sedimentos en los embalses para cada periodo también como parámetro morfo-sedimentario. $\mathrm{El} \mathrm{Q}_{\mathrm{ci}}$ máximo de cada intervalo entre el 1956 y el 1999 corresponde a la estación de Oliana, mientras que, para el periodo 1999-2008, se han utilizado los datos de caudal de salida de la presa de Rialb debido a la disponibilidad de datos en una nueva estación de medida ubicada en dicha presa.

Los bajos valores de correlación entre las variables independientes indican que no están directamente relacionadas entre sí. Para ajustar la ecuación que define la relación entre variables se ha adoptado el análisis stepwise (paso a paso), mientras que para la eliminación inversa de los predictores continuos ha sido aplicado el método de backward elimination. La tolerancia para la matriz inversa es de $\mathrm{F}>5$, valor que determina el grado de significación de una variable en el conjunto de la regresión. El umbral de aceptación de dicho nivel de significación (i.e. valor p) se sitúa en 0.05. A partir de este análisis estadístico se obtienen los coeficientes $\beta$ (coeficientes de regresión parcial estandarizados) y los coeficientes no estandarizados B (entre otros). Los coeficientes $\beta$ definen la ecuación de regresión cuando ésta se obtiene tras estandarizar las variables originales, es decir, tras convertir las puntuaciones directas en típicas. Este proceso permite comparar los coeficientes $\beta$ entre sí; estos coeficientes indican la cantidad de cambio que se producirá en la variable dependiente por cada cambio de una unidad en la correspondiente variable independiente (manteniendo constantes el resto de variables independientes). Dichos coeficientes proporcionan una idea fiable sobre la importancia relativa de cada variable independiente en la ecuación de regresión. En general, una variable tiene tanto más peso (importancia) en la ecuación de regresión cuanto mayor (en valor absoluto) es su coeficiente de regresión estandarizado. Los coeficientes de regresión no estandarizados (o coeficientes B) representan la contribución de cada variable independiente en la predicción de la variable dependiente. Sin embargo, sus valores pueden no ser comparables entre las variables, ya que dependen de las unidades de medida o rangos de las variables respectivas.

\section{Resultados}

\subsection{Hidrología}

\subsubsection{Régimen natural}

Respecto al RNC, la estación de aforos de Organyà (único punto de control libre de regulación en el conjunto del tramo) presenta una aportación media anual de $879 \mathrm{hm}^{3}$, una variabilidad interanual moderada (i.e. $\sigma=246 \mathrm{hm}^{3}, \mathrm{n}_{\mathrm{a}}=51$, donde $\sigma$ es la desviación estándar y $\mathrm{n}_{\mathrm{a}}$ el número de años disponibles) a lo largo de la serie estudiada (1950-2005) y una notable diferencia entre el valor máximo y mínimo de la serie $\left(1417 \mathrm{hm}^{3}\right.$ y $418 \mathrm{hm}^{3}$, respectivamente). La aportación hídrica aumenta a medida que nos desplazamos aguas 
abajo, llegando a los 982 hm³ en Ponts (i.e. estación de Ponts, Fig. 1). Este aumento está atribuido sobre todo a las aportaciones laterales de la Ribera Salada y el río Rialb. En Ponts (aguas arriba del tramo de estudio) el caudal medio es de $27.8 \mathrm{~m}^{3} \mathrm{~s}^{-1}\left(\sigma=7.6 \mathrm{~m}^{3} \mathrm{~s}^{-1}\right.$, $\mathrm{n}_{\mathrm{a}}=51$ ), equivalente a un caudal específico de $8.41 \mathrm{~s} \mathrm{~s}^{-1} \mathrm{~km}^{-1}$, a una escorrentía anual de $265 \mathrm{~mm}$ y a un coeficiente de escorrentía de 0.46 . La variabilidad de los caudales medios diarios, considerada como el cociente entre la diferencia del percentil 10 y 90 del caudal (i.e. $\mathrm{Q}_{90}$ y $\mathrm{Q}_{10}$, respectivamente) y la mediana (i.e. $\mathrm{Q}_{50}$ ), presenta un valor de 2.7. Este valor aumenta a medida que la amplitud del régimen diario de caudales se incrementa y/o cuando la frecuencia de los periodos de caudales bajos aumenta (característica propia del régimen hidrológico mediterráneo, Alcázar y Palau, 2010).

$\mathrm{El}$ régimen natural de caudales (RNC) en Organyà presenta un doble pico, uno entre mayo y junio, debido a la combinación del deshielo y las lluvias de primavera, y otro menor en noviembre. Las crecidas de primavera duran una media de 10 días, pudiéndose prolongarse hasta seis semanas. En otoño las crecidas son de menor duración y magnitud, aunque los mayores eventos hidrológicos del siglo $\mathrm{XX}$ se produjeron precisamente durante esta estación (i.e. octubre de 1907, octubre de 1937 y noviembre de 1982). Por su parte, el río no tiene estiajes debido a las altas aportaciones hídricas de origen pirenaico que moderan la influencia mediterránea en la cuenca.

\subsubsection{Alteración del régimen hidrológico}

Los embalses de Oliana y Rialb (Fig. 1) regulan el caudal del Segre, alterando su RNC. El análisis del $\mathrm{RMC}_{\mathrm{Hb}}$ indica que el embalse de Oliana, a pesar del bajo IR ( 0.1 i.e. el embalse tiene un $10 \%$ de capacidad de regulación de la aportación media anual), produce alteraciones en la estacionalidad, en la variabilidad mensual de las aportaciones y en la variabilidad de los caudales diarios durante la temporada de riego (i.e. de abril a septiembre). El abastecimiento del Canal d'Urgell (Fig. 1) condiciona el almacenamiento de agua con la llegada del deshielo, agua que no es liberada hasta finales de verano (i.e. agosto y septiembre). Esta gestión de los caudales tiene como resultado que la diferencia entre la aportación mensual máxima y mínima se haya reducido un $23 \%$ y que la variabilidad de los caudales diarios haya disminuido un $11 \%$ (Tabla 4). El incremento de la frecuencia de los caudales diarios similares al $\mathrm{Q}_{50}$ aumenta la homogenización de valores de la serie. Aguas abajo del embalse de Rialb ( $I R=0.5$ ), la magnitud, la variabilidad mensual, la estacionalidad y la variabilidad diaria de las aportaciones también se ven afectadas por la gestión del embalse. La demanda asociada al riego, la situación climática del año en curso y las reservas del año anterior marcan el patrón del régimen de caudales salientes o liberados. De octubre a mayo, el embalse retiene hasta un volumen medio de $125 \mathrm{hm}^{3}$ de agua de los caudales entrantes. Durante los meses con mayor aportación, abril y mayo, el embalse llega a retener hasta $82 \mathrm{hm}^{3}$, un $30 \%$ de la escorrentía entrante. En junio, las demandas de riego y el menor caudal propician la liberación de recursos hasta finales de septiembre. Durante esta segunda fase el caudal medio de salida es muy superior al esperado en régimen natural, sobre todo a partir de julio y agosto (i.e. 66 y $48 \%$, respectivamente). Todo ello, suaviza la magnitud de las crecidas de primavera y la severidad del estiaje, atenuando la variabilidad mensual de las aportaciones (i.e. diferencia entre los mínimos y máximos mensuales) de $150 \mathrm{hm}^{3}$ a $110 \mathrm{hm}^{3}$ (Tabla 4). La estacionalidad media de la serie de caudales máximos se produce en mayo y no varía entre el RNC y el RMC. En cambio, debido a las demandas de la actividad agrícola la estacionalidad media de mínimos se 
retrasa de agosto a septiembre y de septiembre a octubre a su paso por el embalse de Oliana y de Rialb, respectivamente (Tabla 4). La variabilidad de los caudales diarios disminuye aguas abajo del embalse a casi la mitad (i.e. 3.2 a 1.8; Tabla 4) debido a i) la homogenización de la frecuencia de caudales salientes entre 1 y $40 \mathrm{~m}^{3} / \mathrm{s}$, ii) la eliminación de caudales superiores a los $200 \mathrm{~m}^{3} \mathrm{~s}^{-1}$ (i.e. 4 casos con un máximo de $407 \mathrm{~m}^{3} \mathrm{~s}^{-1}$ ) y iii) la reducción a la mitad de los caudales entre 100 y 200 $\mathrm{m}^{3} \mathrm{~s}^{-1}$ (i.e. de 35 a 19 casos). Se trata pues de una alteración importante de la variabilidad mensual y diaria, que se incrementa en períodos de intensa sequía (i.e. de 2004 a mediados de 2007) durante los cuales la presa libera reservas que recupera en años húmedos posteriores, por ejemplo entre mediados de 2007 y 2008.

Tabla 4. Caracterización de la magnitud, de la variabilidad mensual y diaria y de la estacionalidad del régimen natural y modificado de caudales habituales (i.e. $R N C$ y $R M C_{H b}$ ) aguas arriba y abajo del embalse de Oliana y la presa de Rialb entre los años 1958-2005 y 2000-2014, respectivamente.

\begin{tabular}{|l|l|c|c|c|c|}
\hline & & \multicolumn{2}{|c|}{$\mathbf{1 9 5 8 - 2 0 0 5}$} & \multicolumn{2}{|c|}{$\mathbf{2 0 0 0 - 2 0 1 4}$} \\
\hline \multirow{2}{*}{ VALORES } & \multicolumn{1}{|c|}{ VARIABLE } & $\begin{array}{c}\text { Organyà } \\
(\mathbf{R N C})\end{array}$ & $\begin{array}{c}\text { Oliana } \\
\left(\mathbf{R M C}_{\mathbf{H b}}\right)\end{array}$ & $\begin{array}{c}\text { Oliana } \\
(\mathbf{R N C})\end{array}$ & $\begin{array}{c}\mathbf{R}^{\text {Rialb }} \\
\left(\mathbf{R M C}_{\mathbf{H b}}\right)\end{array}$ \\
\hline \multirow{3}{*}{$\begin{array}{l}\text { Anuales y } \\
\text { mensuales }\end{array}$} & Magnitud $\left(\mathrm{hm}^{3}\right)$ & 909 & 964 & 889 & 938 \\
\cline { 2 - 6 } & Variabilidad mensual $\left(\mathrm{hm}^{3}\right)$ & 127 & 98 & 150 & 110 \\
\cline { 2 - 6 } & $\begin{array}{l}\text { Estacionalidad } \\
\text { (mes de máxima - mínima) }\end{array}$ & Mayo-Agosto & $\begin{array}{c}\text { Mayo- } \\
\text { Setiembre }\end{array}$ & $\begin{array}{c}\text { Mayo- } \\
\text { Setiembre }\end{array}$ & $\begin{array}{c}\text { Mayo- } \\
\text { Octubre }\end{array}$ \\
\hline Diarios & Variabilidad & 2.75 & 2.4 & 3.2 & 1.8 \\
\hline
\end{tabular}

\subsubsection{Alteración de las crecidas}

Para el análisis del régimen modificado de caudales máximos $\left(\mathrm{RMC}_{\mathrm{Cd}}\right)$ utilizamos como valores de referencia i) la media del caudal máximo anual $\left(\overline{\mathrm{Q}_{\mathrm{C}}}\right)$, ii) el caudal bankfull $\left(\mathrm{Q}_{\mathrm{Bank}}\right)$ calculado tal y como se indica a la metodología y, iii) el caudal medio de las crecidas habituales $\left(\mathrm{Q}_{5}\right)$ de la sección de control situado aguas arriba del punto de impacto. La influencia del embalse de Oliana se estudia a partir a dos series de 40 años de datos completos y temporalmente coincidentes (desde 1958 hasta 2005) entre las estaciones de Organyà y Oliana (Fig. 1). Para este período los caudales $Q_{c}, Q_{B a n k}$ y $Q_{5}$ de la estación de Organyà son de $161 \mathrm{~m}^{3} \mathrm{~s}^{-1}$ (equivalente a un $\left.\mathrm{Q}_{\mathrm{Esp}}=59.61 \mathrm{~s}^{-1} \mathrm{~km}^{-2}\right), 168 \mathrm{~m}^{3} \mathrm{~s}^{-1}\left(62.21 \mathrm{~s}^{-1} \cdot \mathrm{km}^{-2}\right)$ y $75.3 \mathrm{~m}^{3}$ $\mathrm{s}^{-1}\left(27.81 \mathrm{~s}^{-1} \mathrm{~km}^{-2}\right)$ respectivamente. Los resultados de los Índices de Alteración Hidrológica (IAH; ver Tabla 5) muestran un estado Bajo de alteración de la magnitud y frecuencia (IMF), de la estacionalidad (IE) y de la duración (ID) de las crecidas. El estado de modificación de la variabilidad interanual (IV) de las crecidas máximas diarias y las habituales es Moderado. El $\mathrm{Q}_{\mathrm{c}}$ y el $\mathrm{Q}_{\text {Bank }}$ medio presentan un incremento del 8.5\% y del 20\% respectivamente entre los dos puntos de control, mientras que la magnitud de las $\mathrm{Q}_{5}$ no ha experimentado ningún cambio. El citado incremento es sorprendente; una posible explicación radica en el estado de llenado del embalse cuando llega una crecida determinada. Cuando el vaso del embalse está lleno y hay indicios de la llegada de una crecida, la presa empieza a desembalsar caudales superiores a los entrantes. La modificación de los caudales de crecida ha comportado a su vez una mayor alteración de la variabilidad interanual de $\operatorname{los}\left(\overline{\mathrm{Q}_{\mathrm{C}}}\right) \mathrm{y}$ de $\operatorname{los}\left(\mathrm{Q}_{5}\right)$, produciendo un incremento 
en los índices respectivos del 35\% y del 30\%. Los índices de variabilidad se muestran como un indicador interesante para caracterizar este tipo de cambios. En el caso de Rialb se ha trabajado con la estación de aforos de Oliana y los datos de la salida del embalse de Rialb (Fig. 1), con dos series de 11 años de datos completos y temporalmente coincidentes (20002014). Son distintos los índices que determinan el IAH. El índice de alteración de las crecidas máximas anuales y el índice del caudal bankfull $\left(\mathrm{IMF}_{\mathrm{Cm}}\right.$ y $\mathrm{IMF}_{\mathrm{Bank}}$, respectivamente) indican un estado de alteración Moderado (Tabla 5). El análisis del impacto sobre la variabilidad de las crecidas máximas diarias anuales y de las crecidas habituales $\left(\mathrm{IV}_{\mathrm{Cm}} \mathrm{y} \mathrm{IV}_{\mathrm{Ch}}\right.$, respectivamente) determina un estado Moderado de alteración (Tabla 5). El IR (0.5) del embalse de Rialb, la reciente puesta en marcha (1998-99) y el efecto de una importante acequia durante varios años ha incrementado la capacidad de alteración del RNC por parte de la presa. Como ya se indica en la tabla 5, la variabilidad de las crecidas habituales y su estacionalidad son los aspectos más afectados por la regulación del embalse de Rialb, que en el caso de la variabilidad es debido a caudales más homogéneos y de menor rango medio $\left(R_{m}\right)$ anual (por ej. Oliana: $R_{m}=333 \mathrm{~m}^{3} \mathrm{~s}^{-1}$, $\sigma=42$; Rialb: $\left.\mathrm{R}_{\mathrm{m}}=128 \mathrm{~m}^{3} \mathrm{~s}^{-1}, \sigma=24\right)$. La magnitud de $\operatorname{los} \mathrm{Q}_{\mathrm{c}}$ se redujo una media del $35 \%$, implicando una disminución del caudal bankfull al depender del $\mathrm{Q}_{\mathrm{c}}$ (ver Eq. 1).

Tabla 5. Índices de Magnitud y Frecuencia (IMF), de Variabilidad (IV), de Estacionalidad (IE) y de Duración (ID) correspondientes al embalse de Oliana (1958 a 2005) y al embalse de Rialb (2000-2009). Determinación del estado hidrológico correspondiente a cada índice de alteración para el embalse de Oliana y el embalse de Rialb. Todo el conjunto conforman los Índices de Alteración Hidrológica.

\begin{tabular}{|c|c|c|c|c|c|}
\hline \multirow{2}{*}{ CÓDIGO } & \multirow{2}{*}{ ÍNDICE } & \multicolumn{2}{|c|}{ VALOR } & \multicolumn{2}{|c|}{$\begin{array}{l}\text { ESTADO DE } \\
\text { ALTERACIÓN }\end{array}$} \\
\hline & & Oliana & Rialb & Oliana & Rialb \\
\hline $\mathrm{IMF}_{\mathrm{Cm}}$ & Índ. Crecidas Máx. ${ }^{1}$ & $0.92^{1}$ & 0.65 & Bajo & Moderado \\
\hline IMF $_{\text {Bank }}$ & Índ. Caudal bankful ${ }^{1}$ & $0.91^{1}$ & 0.76 & Bajo & Moderado \\
\hline $\mathbf{I M F}_{\mathrm{Ch}}$ & Índ. Crecidas Habituales & 1.00 & 0.88 & Bajo & Bajo \\
\hline $\mathbf{I} \mathbf{V}_{\mathrm{Cm}}$ & $\begin{array}{l}\text { Índ. Variabilidad Crecidas Máx. } \\
\text { diarias anuales }{ }^{1}\end{array}$ & $0.74^{1}$ & 0.72 & Moderado & Moderado \\
\hline $\mathbf{I V}_{\mathrm{Ch}}$ & Índ. Variabilidad Crecidas Habituales ${ }^{1}$ & $0.77^{1}$ & 0.67 & Moderado & Moderado \\
\hline $\mathbf{I E}_{\mathrm{Cd}}$ & Índ. Estacionalidad Crecidas & 1.00 & 0.67 & Bajo & Moderado \\
\hline $\mathbf{I D}_{\mathrm{Cd}}$ & Índ. Duración Crecidas ${ }^{1}$ & $0.91^{1}$ & $0.85^{1}$ & Bajo & Bajo \\
\hline
\end{tabular}

${ }^{1}$ Cuando el índice obtiene un valor mayor que 1 (i.e. la magnitud es superior aguas abajo que aguas arriba) se sustituye el valor calculado por su inverso debido al requerimiento para el cálculo del IAG donde es necesario que los índices parciales (i.e. IAH) sean menores que 1.

Para completar el análisis del $\mathrm{RMC}_{\mathrm{Cd}}$ se analizó la magnitud (i.e. pico de caudal) de las crecidas de 50 años de período de retorno $\left(\mathrm{T}_{50}\right)$ aguas arriba y abajo de los embalses y se caracterizaron diversos hidrogramas de crecida entre 1982 y 2010 . El ajuste para 50 años de los caudales máximos instantáneos $\left(\mathrm{Q}_{\mathrm{ci}}\right)$ aguas abajo de Oliana indica una reducción del 10\%; en cambio, el ajuste con $\operatorname{los} \mathrm{Q}_{\mathrm{c}}$ no indica ninguna alteración 
significativa. Por el contrario, Rialb causa una importante alteración de la magnitud y de la frecuencia de los caudales anuales máximos (i.e. de crecida), reduciendo de media un $41 \%$ la magnitud de los caudales estimados para un mismo periodo de retorno.

La representación de la valoración del estado de alteración global (IAG) se muestra en las Figs. 3a y 3b (ver sección metodológica para más detalles). En ellas se recogen los cambios en los caudales de crecida. La alteración resultante de Oliana es baja (IAG = 0.66) con tendencia a moderada según la clasificación adoptada. En el caso de Rialb la alteración es moderada $(\mathrm{IAG}=0.46$ ). En comparación con Oliana y teniendo en cuenta la mayor capacidad de regulación de esta presa la calificación parece razonable. No obstante, hay que recordar que la evaluación del impacto de este embalse se ha realizado con una serie de datos de once años, hecho que podría llevar a una cierta distorsión en el índice obtenido.

La segunda fase del análisis incluye la caracterización de 17 hidrogramas de crecida (i.e. 10 de ordinarias y 7 de extraordinarias). Las Figs. 4 y 5 muestran dos ejemplos representativos. Estas crecidas presentan repetidamente un patrón de alteración de la forma de los hidrogramas salientes de cada embalse respecto de los entrantes en función de la capacidad y el llenado del vaso en cada momento, así como de las necesidades operativas de las presas. El embalse de Oliana es relativamente pequeño $(I R=0.1$ ), lo que altera poco los caudales extraordinarios pero sí los ordinarios, sobre todo en otoño y al principio de la primavera cuando se encuentra más vacío. Esta situación implica una laminación parcial e incluso total del evento ordinario (Fig. 4). En tiempo de deshielo, si el vaso está casi lleno se produce un tercer patrón basado en el retraso de la crecida y la eliminación de las fluctuaciones entre el día y la noche típicas de un régimen pluvio-nival (Fig. 5). Con la campaña de riego, a mediados de primavera y principio de verano, se intenta retener la máxima cantidad de recursos posibles, originando caudales muy modestos aguas abajo con continuas fluctuaciones (i.e. dientes de sierra) para dar respuesta a las demandas hídricas de los canales. La inauguración en 1999 de la presa de Rialb implica una gestión de los embalses en serie, hecho que acentúa el patrón de modificación de caudales ya descrito (Figs. 4 y 5).

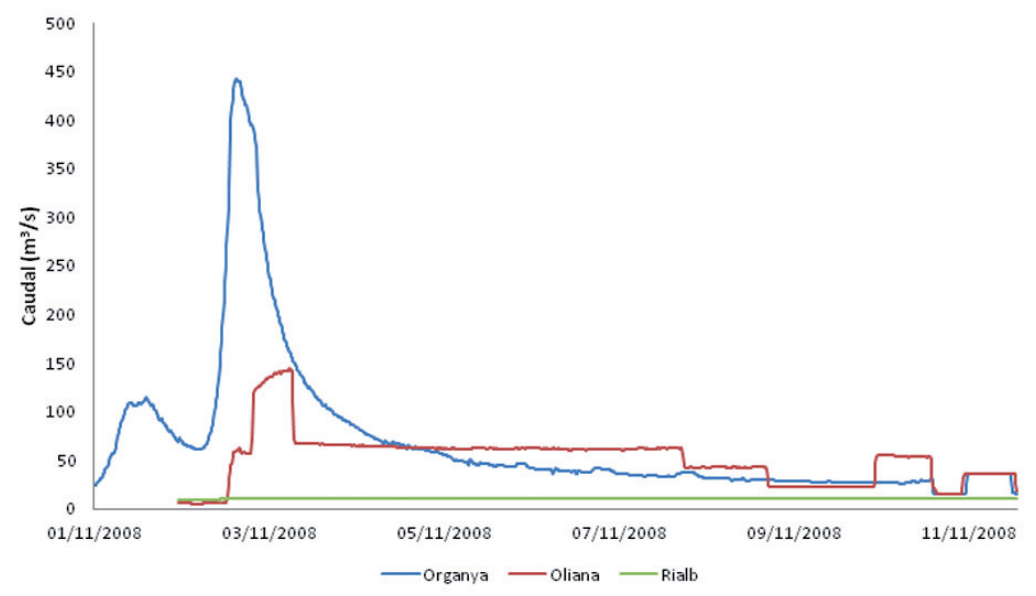

Figura 4. Crecida extraordinaria registrada en las estaciones de aforo de Organyà (línea azul) y de Oliana (línea roja) y en la salida del embalse de Rialb (línea verde) durante noviembre de 2008. 


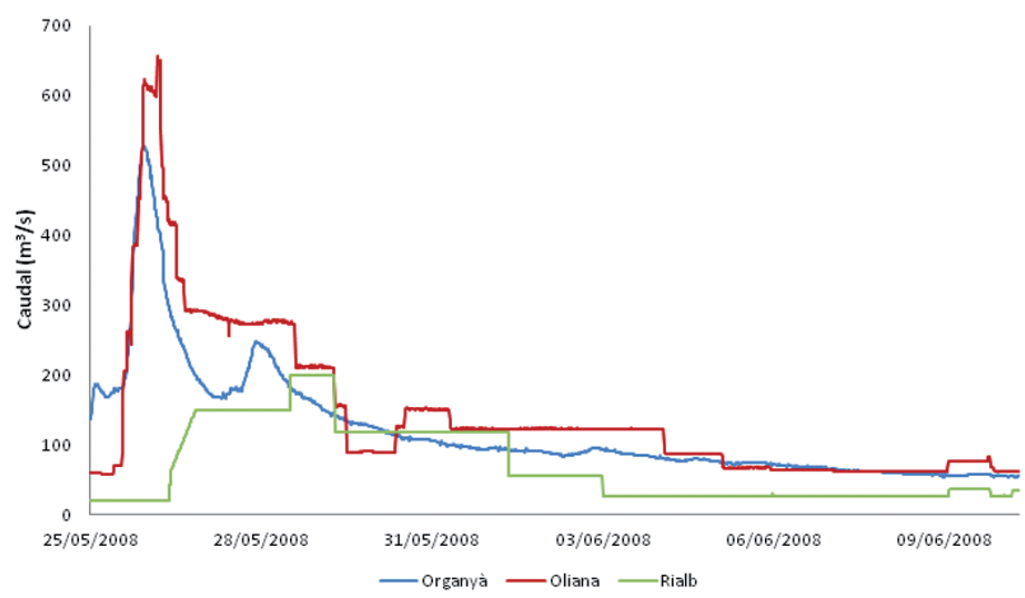

Figura 5. Crecida extraordinaria registrada en las estaciones de aforo de Organyà (línea azul) y de Oliana (línea roja) y en la salida del embalse de Rialb (línea verde) durante mayo y junio de 2008. El embalse de Oliana se encuentra casi lleno y desembalsa agua para reducir el riesgo de sobrepasar el nivel máximo de almacenamiento. Esta situación conlleva un incremento del caudal natural máximo observado en Organyà.

\subsection{Alteración morfo-sedimentaria}

\subsubsection{Sedimentación en embalses}

La capacidad de retención media de sedimentos en el embalse de Oliana estimada a partir de la curva Brune (1953) es del 87\% (sobre una aportación hídrica media anual de $879 \mathrm{hm}^{3}$ y una capacidad de almacenamiento inicial de $101 \mathrm{hm}^{3}$ ); si se utilizan los extremos de la curva (i.e. según el autor correspondería a sedimentos en suspensión más gruesos y más finos, donde el primero se encuentra altamente floculado y el segundo contiene una alta dispersión coloidal), la capacidad de retención oscilaría entre el 95 y el $80 \%$. En el caso del embalse de Rialb $\left(403 \mathrm{hm}^{3}\right)$ entre el 92 y el $99 \%$ de la carga transportada en suspensión es retenida por el embalse. El error medio del método al no considerar que no siempre el embalse está lleno oscila entre el 2 y el $4 \%$ en el caso del embalse de Oliana.

La tabla 6 muestra valores de aterramiento del embalse de Oliana entre 1985 y 2007 (datos del Centro de Estudios y Experimentación de Obras Públicas extraídos de Batalla y Vericat, 2011). Los resultados muestran una reducción del 22\% entre ambos años lo que equivale a $23 \mathrm{hm}^{3}$ de sedimentos; a partir de Brune estimamos que alrededor de un $13 \%$ de sedimentos finos escapan de esta la presa, y con ello la carga sólida anual del Segre aguas abajo sería de ca. $460000 \mathrm{~m}^{3}$. A partir del rango de densidades de los sedimentos retenidos en diferentes embalses de la cuenca del río Ebro $\left(1.1 \mathrm{t} \mathrm{m}^{-3} \mathrm{y}\right.$ $1.56 \mathrm{t} \mathrm{m}^{-3}$; para más información ver Batalla y Vericat, 2011), y de la pérdida anual de almacenamiento estimada para Oliana, se calcula que llegarían cada año entre 510000 y 720000 toneladas de sedimentos al embalse de Rialb desde aguas arriba, con lo que 
la transferencia teórica aguas abajo (i.e. al tramo de estudio) oscilaría entre 65000 y 93 000 toneladas anualmente (según la capacidad de retención de Rialb y sin considerar las aportaciones de tributarios que son relativamente mínimas). No se dispone de datos batimétricos del embalse de Rialb que permitan corroborar estas estimaciones.

Tabla 6. Cambios en la capacidad de almacenamiento del embalse de Oliana desde su construcción; pérdida de capacidad y retención de sedimentos.

\begin{tabular}{|l|l|r|}
\hline PERIODO & DATOS BATIMÉTRICOS & \\
\hline $\mathbf{1 9 5 8}$ & Volumen inicial $\left(\mathrm{hm}^{3}\right)$ & 101.1 \\
\hline $\mathbf{1 9 5 8 - 1 9 8 5}$ & Volumen final $\left(\mathrm{hm}^{3}\right)$ & 85.8 \\
\hline & Pérdida capacidad $(\%)$ & 16.0 \\
\hline & Acumulación anual $\left(\mathrm{hm}^{3}\right)$ & 0.57 \\
\hline $\mathbf{1 9 8 5 - 2 0 0 7}$ & Volumen final $\left(\mathrm{hm}^{3}\right)$ & 78.4 \\
\hline & Pérdida capacidad $(\%)$ & 8.0 \\
\hline & Acumulación anual $\left(\mathrm{hm}^{3}\right)$ & 0.34 \\
\hline $\mathbf{1 9 5 8 - 2 0 0 7}$ & Volumen final $\left(\mathrm{hm}^{3}\right)$ & 78.4 \\
\hline & Pérdida capacidad $(\%)$ & 22.0 \\
\hline & Acumulación anual $\left(\mathrm{hm}^{3}\right)$ & 0.46 \\
\hline
\end{tabular}

\subsubsection{Extracción de áridos}

Según los datos disponibles y teniendo en cuenta las consideraciones indicadas en el apartado metodológico, durante el período 1973-2009 se calcula que se han extraído más de 2.5 millones de $\mathrm{m}^{3}$ de sedimentos desde aguas abajo del embalse de Oliana a Alòs de Balaguer. Este valor equivale al 33\% del material extraído en todo el Segre, y corresponde a una extracción media de 72600 toneladas anuales. Las extracciones producidas aguas arriba del embalse de Rialb después de su construcción no se han incluido en el análisis morfo-sedimentario del tramo de estudio al no influir de manera directa en el estado geomorfológico del río aguas abajo. Tal y como muestra la Fig. 6, las extracciones aguas abajo del embalse de Rialb se concentraron en la zona del tramo \#2. El material extraído corresponde normalmente a fracciones granulométricas gruesas (gravas y cantos) que son transportadas como carga de fondo y determinan la morfología del cauce (Church, 2006). La proporción de la carga de fondo sobre la carga total varía a lo largo del tiempo en relación con la magnitud de las crecidas y la disponibilidad y suministro de sedimentos desde aguas arriba. De la misma forma, el estado morfo-sedimentario del cauce también condiciona la disponibilidad de materiales gruesos (i.e. acorazamiento). Según Vericat y Batalla (2010), en el caso de la Ribera Salada (principal afluente de la intercuenca Oliana-Rialb, Fig. 1), la proporción de la carga de fondo sobre el total de la aportación sedimentaria anual es 
del 4\% (i.e. años hidrológicos medios). Aplicando este valor a la sedimentación en el embalse de Oliana se estima que la retención de material grueso sería de $18400 \mathrm{~m}^{3}$; la comparación de este valor con el volumen extraído indica que la actividad extractiva representa el 395\% de la producción media anual de material grueso de la cuenca. Pese a la incertidumbre asociada a los cálculos, los resultados indican que la minería de áridos habría excedido de manera muy notable la aportación sedimentaria media anual de la cuenca, contribuyendo de esta manera al déficit estructural de sedimentos de la cuenca por parte de las dos grandes presas. La Fig. 7 muestra que la mayoría de las extracciones de áridos se ejecutaron tras la crecida de 1982 (i.e. el período 1983-2008 concentra el 80\% del total de las extracciones). En el periodo 1993-1999 se extrajo el $48 \%$ del total del volumen (i.e. más de 1.2 millones de $\mathrm{m}^{3}$ ), siendo el periodo en el que se extrae la máxima cantidad del total del material extraído. Tal y como se muestra en el estudio morfológico (sección 4.3.), la riada de 1982 generó una alta movilidad, lo que aumentó considerablemente la superficie activa del cauce reduciendo la extensión de la vegetación de ribera que ya estabilizaba unidades morfosedimentarias identificadas en 1956 (año de referencia). La principal consecuencia de esta reactivación fluvial momentánea fue el aumento de la superficie expuesta (libre de vegetación) ofreciendo materiales más atractivos desde el punto de vista extractivo y comercial; aun así, conviene tener en cuenta que las extracciones se realizaron en un tramo de río que ya experimentaba los efectos del desequilibrio sedimentario inducidos por el cierre del embalse de Oliana en 1959.

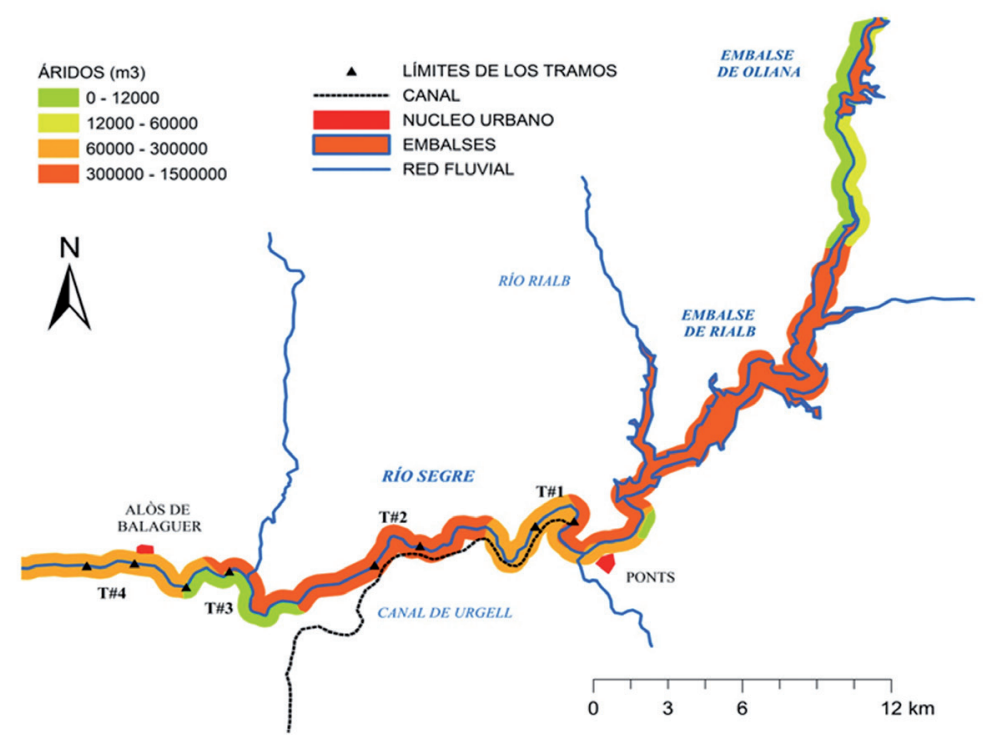

Figura 6. Volumen total de áridos extraídos en el río Segre desde Oliana a Alòs de Balaguer para el período 1973-2009. Los volúmenes han sido clasificados a escala municipal. La cuantificación se ha hecho a partir del registro de licencias de la Confederación Hidrográfica del Ebro, donde se especifica el año de la concesión, el volumen y la localización (municipio). 

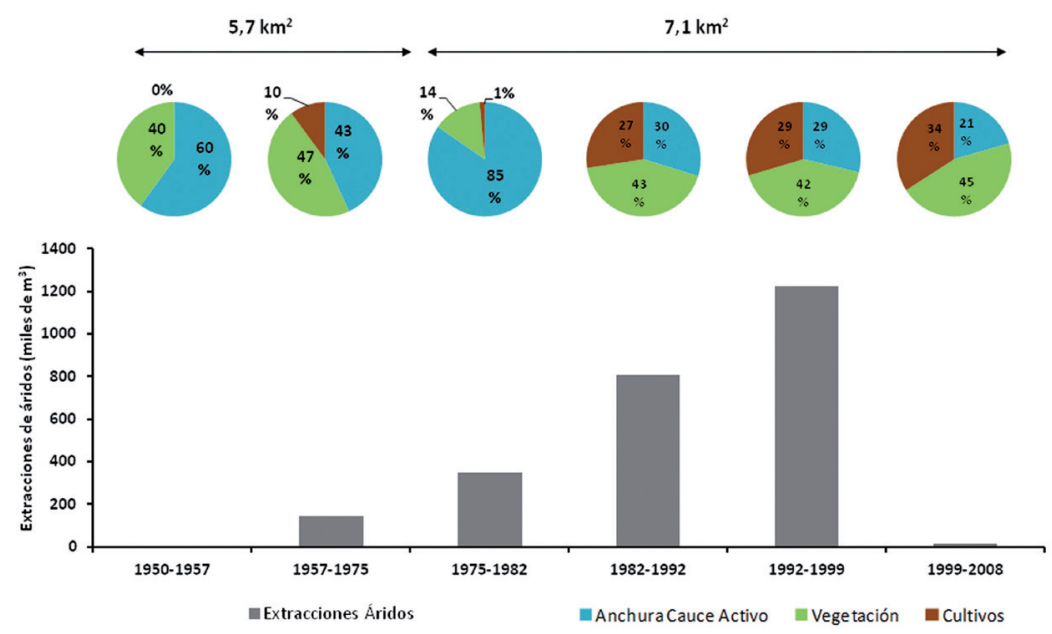

Figura 7. Evolución cronológica de la anchura del cauce activo y de la superficie vegetada (vegetación de ribera y barras centrales vegetadas) y de cultivo en relación a las extracciones de áridos en el tramo medio del Segre entre los años 1956 y 2008. La extensión del área de análisis pasa de $5.7 \mathrm{~km}^{2}$ a $7.1 \mathrm{~km}^{2}$ después de la crecida del noviembre de 1982. La magnitud del caudal máximo instantáneo anual indica la competencia de los caudales entre cada intervalo de estudio.

\subsection{Evolución morfológica}

La cartografía de las diferentes formas fluviales permite comparar su evolución de manera cuantitativa (Tabla 7). La Fig. 8 muestra un ejemplo de cambio en un tramo ubicado $32.5 \mathrm{~km}$ aguas abajo de la presa de Rialb. La evolución de este sector ilustra la dinámica observada en el conjunto del área de estudio.

Tabla 7. Evolución temporal de la extensión superficial de las unidades sedimentarias y morfológicas del tramo medio del Segre entre los años 1956 y 2008.

\begin{tabular}{|c|c|c|c|c|c|c|c|}
\hline \multirow{2}{*}{ CODIGO } & \multirow{2}{*}{ DENOMINACIÓN } & \multicolumn{6}{|c|}{ EXTENSIÓN EN PLANTA $\left(\mathbf{k m}^{2}\right)$} \\
\hline & & 1956 & 1975 & 1982 & 1992 & 1999 & 2008 \\
\hline $\mathrm{CAB}$ & Cauce de Aguas Bajas & 1.02 & 1.52 & 1.82 & 1.46 & 1.34 & 1.21 \\
\hline$\overline{\mathrm{BCA}}$ & Barra Central Activa & 0.14 & 0.05 & 0.19 & 0.02 & 0.01 & 0.01 \\
\hline $\mathbf{B C V}$ & arra Cent & 0.01 & 0.00 & 0.00 & 0.01 & 0.00 & 0.06 \\
\hline BLA & Barra Lat & 2.26 & 0.91 & $4.04^{1}$ & 0.64 & 0.71 & 0.26 \\
\hline $\mathbf{C A}$ & Cauce & 3.41 & 2.48 & 6.05 & 2.12 & 2.06 & 1.48 \\
\hline CUL & Cultivos & 0.00 & 0.58 & 0.11 & 1.95 & 2.12 & 2.45 \\
\hline IDF $=\mathrm{CA} / \mathrm{AB}$ & Índice de dinámica fluvial ${ }^{2}$ & 3.36 & 1.63 & 3.32 & 1.46 & 1.54 & 1.22 \\
\hline
\end{tabular}

${ }^{1}$ Incluye todo el cauce activo más la zona afectada por la deposición de sedimentos movilizados durante la crecida del noviembre del 1982.

${ }^{2}$ Estos índices podrían estar influenciados por las condiciones de caudal en el momento que se adquirió la fotografía aunque las tendencias se mantendrían. 

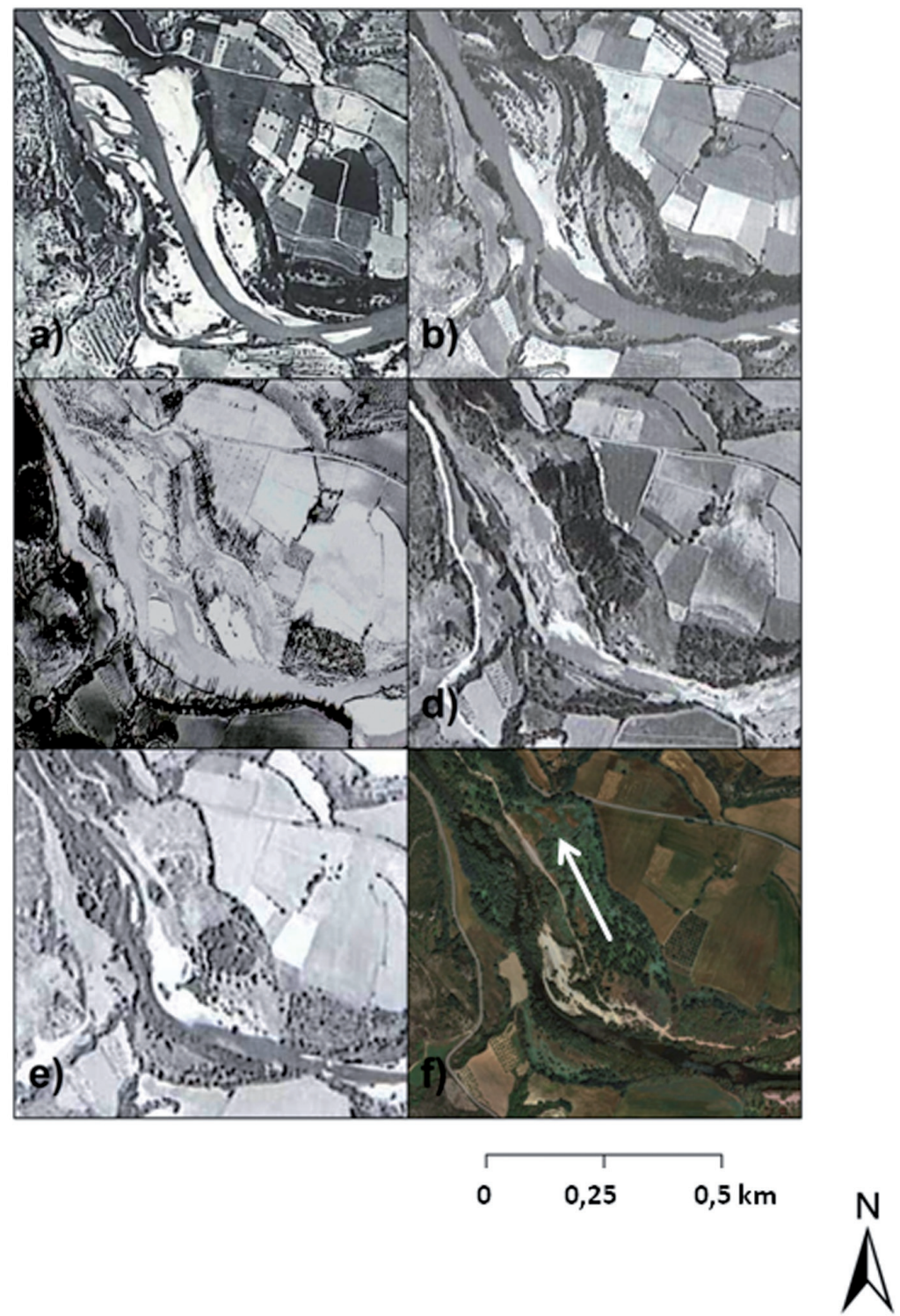

Figura 8. Evolución morfológica entre los años 1956 y 2008 de un tramo representativo del río Segre situado a 800 metros aguas arriba de la población de Alòs de Balaguer (Figura 1). En (a) 1956 se parte de una situación de inestabilidad en la que los depósitos sedimentarios son activos. En el año 1975 (b) hay una reducción de las unidades sedimentarias activas. Con la riada del noviembre de 1982 (c) se genera una nueva situación morfo-sedimentaria (i.e. reinicio) con muchos cambios en el patrón y la forma del cauce, al igual que en el número y extensión de las unidades morfológicas activas (ver Tabla 7). Las imágenes del (d) 1992, (e) 1999 y (f) 2008 muestran la desaparición progresiva de la mayoría de las unidades sedimentarias activas y una continua contracción del cauce producido por el aumento de la regulación del régimen de crecidas, así como la extracción de sedimentos. La dirección del flujo es SE-NO. 
En 1956 los depósitos sedimentarios de todo el tramo se muestran muy activos y con una mínima presencia de vegetación, hecho que muestra que la dinámica fluvial es notable. La actividad sedimentaria era frecuente, lo que limitaba la presencia de vegetación en las barras. Los depósitos sedimentarios activos se habían reducido notablemente en 1975 mientras que la presencia de la vegetación había aumentado considerablemente. La crecida de noviembre de 1982, la segunda más importante de todo el siglo XX, regeneró el sistema debido a su elevada competencia. La magnitud de este evento provocó cambios notables en el patrón de drenaje y la forma del cauce, al igual que en el número y la extensión de las unidades activas (Figs. 7 y 8). De la misma forma, se observa una clara reducción de la vegetación de ribera. Posteriormente, el cauce tendió de nuevo a la estabilización, hecho que favoreció su ocupación por vegetación en zonas que hasta hacia poco habían sido activas. Se observa también un incremento de las superficies de cultivos en áreas cercanas al río anteriormente inundables (Fig. 7). En este periodo (1982-1992) la superficie ocupada por la vegetación en el cauce activo se triplica (de 1 a $3 \mathrm{~km}^{2}$ ). En la década de 1990 se observa un repunte de la actividad geomorfológica como consecuencia de crecidas de cierta magnitud (hasta $\mathrm{T}_{10}$ ) entre 1994 y 1996. Esta actividad se traduce en un nuevo incremento de las barras activas (10\%) y una cierta reducción de la vegetación (i.e. hasta un 5\% según el tramo). Esto favorece de nuevo el incremento de las actividades extractivas (más disponibilidad sedimentos) a finales de los años noventa.

La relación entre la superficie del cauce activo (definido como sección fluvial formada por las unidades sedimentarias activas más el cauce de aguas bajas y que es capaz de drenar avenidas ordinarias) y del cauce de aguas bajas (parte del cauce que ocupan los caudales de base), permite determinar el grado de libertad que el río dispone para modificar su curso en períodos de elevada competencia. El cociente entre ambos, expresado de forma adimensional (Tabla 7), indica la movilidad potencial del cauce en cada momento histórico. Este cociente o Índice de Dinámica Fluvial (IDF) será cercano a 1 cuando el cauce de aguas bajas ocupa la mayor parte de la zona activa; mientras que los valores $>1$ corresponden a tramos en los que el río cambia de patrón de drenaje con cierta frecuencia (i.e. más movilidad potencial). La movilidad observada en 1956 muestra que 1/3 de la superficie activa estaba ocupada por el cauce de aguas bajas (IDF = 3.4). La estabilización morfo-sedimentaria posterior (atribuida a una menor disponibilidad de sedimentos y a la reducción de energía disponible para el transporte por el efecto del embalse de Oliana) generó una reducción del IDF a valores próximos a 1 (i.e. prácticamente la totalidad de la superficie activa está ocupada por el cauce de aguas bajas) y, con ello, los caudales liberados por la presa activan tan sólo una superficie mínima del cauce. Así, en esta situación la mayoría de los procesos de erosión y transporte ocurren en el propio cauce de aguas bajas. Por el contrario, en situaciones extremas como la crecida de 1982 el caudal inunda de nuevo toda el área activa descrita en la situación de referencia (1956, Fig. 8), los procesos de erosión lateral son importantes, y el índice recupera valores iniciales (i.e. IDF $=3.3$ ). El resultado es un reajuste puntual del sistema con unas nuevas condiciones morfológicas y sedimentarias. Posteriormente, el IDF se reduce hasta 1.2 en el año 2008, lo que indica una pérdida de movilidad del cauce (i.e. cauce colonizado por vegetación de ribera y ocupado por campos de cultivo) y un aumento de la estabilidad del sistema. La reducción de la competencia de los caudales 
liberados provoca una dinámica asociada a la incisión y acorazamiento del cauce principal; ambos fenómenos se observan actualmente a lo largo de todo el tramo de estudio. La incisión en todo el tramo es del orden de 0.5-1 m, llegando en diversos puntos a aflorar la roca madre. Por otra parte, el tamaño del $\mathrm{D}_{50-\mathrm{S}}$ en zonas todavía aluviales es de $43 \mathrm{~mm}$. No hay datos del material subsuperficial del Segre medio. Las observaciones de campo indican que el material subsuperficial es claramente más fino que el superficial. Así, con el objetivo de estimar el índice de acorazamiento potencial del medio Segre, se ha utilizado un percentil 50 subsuperficial característico de la Ribera Salada. La Ribera Salada es el principal tributario aguas arriba del área de estudio (Fig. 1). Comparte factores morfométricos, geológicos y climáticos con el Segre. Allí, el $\mathrm{D}_{50-\mathrm{ss}}$ es de 19.5 mm (Crozzoli y Batalla, 2003; Vericat y Batalla, 2010). Mediante los percentiles 50 para el material superficial y subsuperficial se ha calculado el índice de acorazamiento ( $\mathrm{I}_{\mathrm{a}}$ ). El $I_{a}$ en el Segre medio es importante $\left(I_{a}=2.2\right)$ pero variable entre tramos (i.e. \#1, 1.25; \#2, 3.5; \#3, 1.7 y \#4, 2.5). Esta variabilidad puede deberse a la entrada de tributarios (por ej. Llobregós) que aportan material más fino (gravas finas, arena) que puntualmente reducen el acorazamiento y confieren más movilidad al lecho, y a un menor volumen de extracción de áridos por longitud de río (por ej. el tramo \#1, Fig. 6).

\subsection{Competencia hidráulica}

La progresiva estabilización del cauce va acompañada generalmente de un aumento del tamaño medio de los materiales superficiales (por el lavado de finos aguas abajo y/o por su percolación entre las gravas i.e. winnowing, Rice y Church, 1998); por esta razón, la competencia de los caudales circulantes deber ser cada vez mayor para movilizar los materiales del lecho y producir transporte de fondo. Este proceso de retroalimentación entre forma y proceso (i.e. reajuste en el perfil longitudinal del río) se interrumpe por i) la ocurrencia de crecidas de elevada magnitud, que ponen en movimiento la coraza detrítica superficial y los materiales subsuperficiales atrapados debajo de ella. Bajo tales condiciones se renueva la granulometría del lecho, iniciándose un periodo de mayor inestabilidad, como el observado después de 1982. Otro proceso que puede interrumpir este comportamiento es ii) la incisión del lecho hasta llegar a la roca madre. En este trabajo planteamos un análisis de competencia en base a la modelización hidráulica de caudales de crecida en cuatro sub-tramos seleccionados (Fig. 1), cuyas características se sintetizan a continuación:

Tramo \#1: Tramo meandriforme (i.e. Índice de Sinuosidad [IS] = 1.83; según Schumm, 1963) con amplia barra lateral (point bar), cubierta por vegetación arbustiva y arbórea, depósitos aluviales residuales y río circulando sobre roca madre en la parte cóncava del meandro $\left(\mathrm{I}_{\mathrm{a}}=1.3\right)$.

Tramo \#2: Tramo ligeramente sinuoso (IS = 1.6) con barra central cubierta parcialmente por vegetación (BCV) arbustiva y arbórea, $\mathrm{I}_{\mathrm{a}}=3.5$ y cauce de aguas bajas sobre roca madre.

Tramo \#3: Tramo rectilíneo (IS = 1.2) con barras laterales abiertas y sin vegetación, y acumulaciones superficiales de arena y gravas finas $\left(I_{a}=1.7\right)$. 
Tramo \#4: Tramo encajado y rectilíneo (IS = 1.2), con depósitos aluviales en altura desconectados del cauce actual, presencia de grandes bloques (i.e. diámetro métrico), parcheados por materiales finos de frecuente movilización $\left(I_{a}=2.5\right)$.

En cada uno de los tramos se ha calculado la tensión crítica efectiva $\left(\tau_{\mathrm{c}-\mathrm{Di}}\right)$ requerida para movilizar los percentiles característicos $\left(\mathrm{D}_{\mathrm{i}}\right)$ de las distribuciones granulométricas superficiales (Tabla 8). Los resultados indican que las condiciones hidráulicas necesarias para generar inestabilidad en el tramo \#1 son inferiores a las obtenidas para el resto de tramos. Los tramos 2, 3 y 4, a pesar de tener una pendiente semejante al tramo 1 (0.2$0.3 \%$ ), presentan una granulometría superficial más gruesa que genera más estabilidad en el lecho y hace que las tensiones críticas requeridas para movilizar los sedimentos sean alcanzadas, teóricamente, con menos frecuencia. Los caudales competentes teóricos se han comparado con los períodos de retorno de la serie de Oliana (Tabla 8). Se observa que durante crecidas de baja magnitud y alta frecuencia (por ej. periodos de retorno 2 años, $\mathrm{T}_{2}$ ), buena parte (i.e. $\leq \mathrm{D}_{90-\mathrm{S}}$ ) del material superficial del tramo \#1 teóricamente se moviliza. En el tramo \#2, bajo estas mismas condiciones, sólo las fracciones más finas (i.e. $\leq \mathrm{D}_{16-\mathrm{S}}$ ) experimentan transporte, así como las fracciones medias (i.e. $\leq \mathrm{D}_{50-\mathrm{S}} \mathrm{y} \leq \mathrm{D}_{60-\mathrm{S}}$ ) en el caso de los tramos 2 y 3 , respectivamente. Las crecidas de menor frecuencia, con un caudal circulante igual o superior a $\mathrm{Q}_{5}$, consiguen movilizar la totalidad de las fracciones granulométricas del material superficial del lecho en el tramo 1. Por el contrario, en el tramo \#2, incluso bajo condiciones hidráulicas de muy alta magnitud (i.e. $\mathrm{Q}_{50}$ ), el caudal sólo consigue movilizar el material con tamaño inferior al $\mathrm{D}_{60-\mathrm{s}}$, dando muestra de gran estabilidad del lecho. El menor calibre de las fracciones granulométricas medias y altas (i.e. $\mathrm{D}_{50-\mathrm{s}} \mathrm{y}_{84-\mathrm{s}}$ ), junto a una mayor competencia hidráulica del sistema para caudales de una frecuencia igual o superior a $\mathrm{T}_{5}$ en $\operatorname{los}$ tramos 3 y 4 , inducen a la movilización total del material superficial del lecho.

La regulación por presas genera una reducción importante de la frecuencia y de la magnitud de las crecidas y, por consiguiente, de los caudales efectivos, y las condiciones hidráulicas resultantes son muy inferiores a las producidas en condiciones naturales. En condiciones de baja movilidad, el intercambio de materiales entre las capas superficial y subsuperficial del cauce es mínimo. No se disponen series de datos suficientemente largas (por ejemplo series de fotografías aéreas) para analizar el impacto del embalse de Rialb con la misma precisión que se ha hecho con el de Oliana. No obstante, se puede aproximar la frecuencia de inestabilidad mediante el $\mathrm{Q}_{\mathrm{n}}$ (i.e. caudal medio diario) registrado en la salida de la presa de Rialb para el periodo 2001-2007 y los umbrales de movilidad que dichos caudales potencialmente generarían en cada uno de los tramos. Se observa que tan sólo en el mejor de los casos y de forma puntual (1 vez en 7 años) se darían las condiciones para movilizar el $\mathrm{D}_{84-\mathrm{s}}$ del tramo más dinámico (\#1). Antes de la puesta en funcionamiento de la presa de Rialb, el régimen hidrosedimentario del Segre medio estaba controlado únicamente por Oliana, lo que, explica por qué aún existen zonas con depósitos activos, por ejemplo en el tramo \#1. La hipótesis es que estos tramos vayan desapareciendo cuando el río llegue a un nuevo ajuste hidrodinámico como consecuencia de la revegetación, el acorazamiento y la incisión del lecho. Modelos evolutivos similares han sido descritos por ejemplo en el tramo bajo del río Ebro (Vericat et al., 2006). 

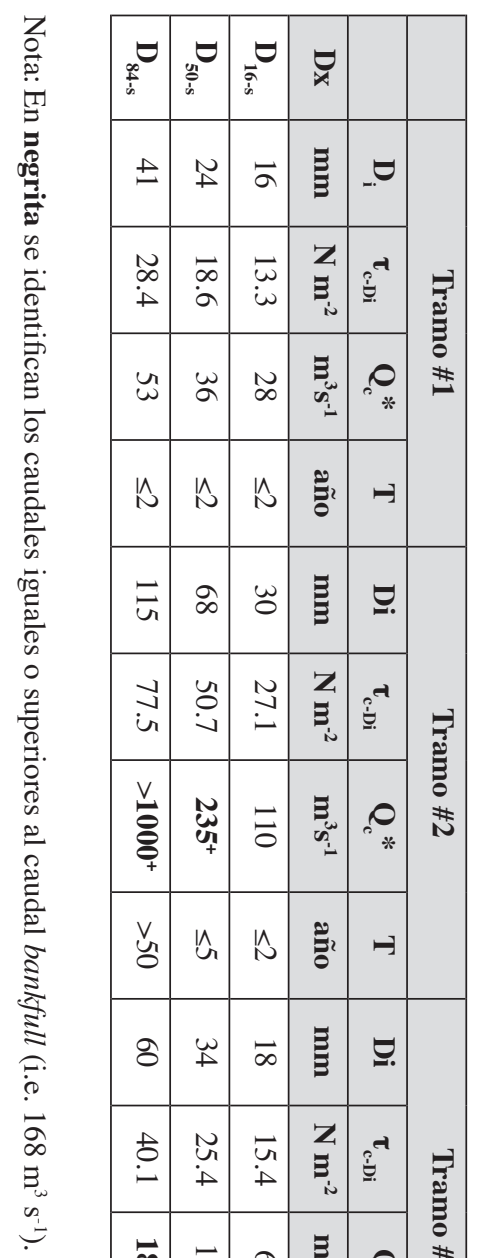

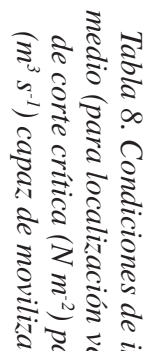

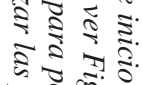

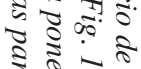

군

ฐ 200

5
0
0
0

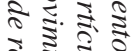

च

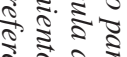

ᄀ

ฐ. ई ई

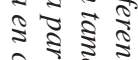

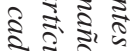

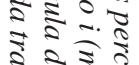

क.

ㄱ. ㄱ.

क क 5

2 क

(2. $\frac{3}{3} \frac{1}{5}$

ว. 3

2 के ई

के इ के

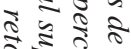

2.

ई ฐ. के

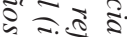

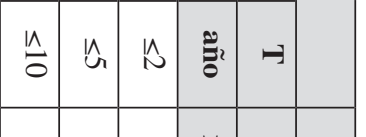

$\frac{1}{2.8} 8$

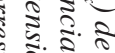

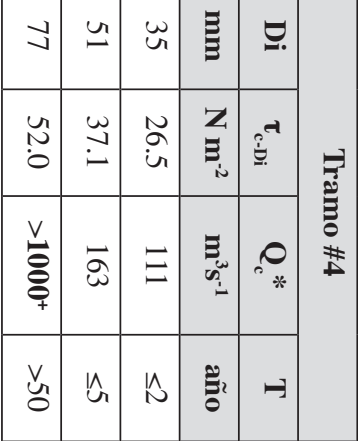

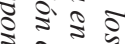

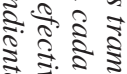

क :

5. 5 ह

इ10

इ

हิ

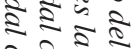

3.

नें $\frac{2}{2}$. 


\subsection{Alteración hidromorfológica: relación causa-efecto}

Las alteraciones hidromorfológicas del tramo medio del Segre se han analizado a partir de un modelo de regresión multivariante que tiene como variables independientes el caudal máximo instantáneo $\left(\mathrm{Q}_{\mathrm{ci}}\right.$ datos de la estación de Oliana primero y a partir del 1999 de la presa de Rialb), el volumen anual de áridos extraídos del sistema fluvial y los sedimentos capturados en el embalse de Oliana para cada uno de los seis periodos estudiados. En la tabla 9 se muestran las variables independientes que mejor explican la varianza de cada variable dependiente analizada: Cauce de Aguas Bajas (CAB), Barra Lateral Activa (BLA), Barra Central Activa (BCA) y Cauce Activo (CA). También se presentan los coeficientes de regresión parciales estandarizados ( $\beta$, ver sección metodológica para más detalles). El $\mathrm{Q}_{\mathrm{ci}}$ máximo de cada periodo se presenta como la variable que mayor influencia ejerce en la evolución de las unidades morfológicas. Esta variable controla la anchura activa del cauce y su disminución contribuye a la estabilización de las barras, tal como se aprecia en la evolución temporal de su extensión (Tabla 10). $\mathrm{El} \mathrm{Q}_{\mathrm{ci}}$ es un claro indicador de la intensidad de energía máxima que se libera anualmente en el cauce, de modo que puede considerarse responsable de la movilización de los sedimentos y de la configuración de la morfología fluvial en términos globales. Además, al incorporar al análisis la extracción de sedimentos, el modelo nos permite resaltar la importancia de la disponibilidad de sedimentos en la dinámica del cauce (de manera complementaria al régimen de crecidas). La continua reducción en la disponibilidad de sedimentos debido a las actividades extractivas (en un medio ya fuertemente afectado por un déficit estructural asociado a la retención de materiales en los embalses) ha reducido año tras año la presencia de unidades sedimentarias activas, sobre todo las barras centrales (Tabla 10). El cauce de aguas bajas, igual que el resto de unidades morfológicas, se contrae con la pérdida de energía (i.e. magnitud) que conlleva la regulación de las crecidas por parte de los embalses de Oliana y Rialb. Aun así, la disminución de la dinámica sedimentaria induce a la expansión del cauce de aguas bajas, efecto contrario al observado en las otras unidades morfológicas que componen el cauce activo.

Tabla 9. Coeficientes $\beta$ de las relaciones entre las variables independientes $\left(Q_{\text {cimax }}\right.$, retención de en embalses y extracciones de áridos) y las unidades morfológicas ( $A B, B L A, B C A$ y $C A$ ) después de la aplicación de la regresión múltiple (ver Tabla 2 para las abreviaturas). La última columna muestra el coeficiente de determinación del modelo de regresión.

\begin{tabular}{|c|c|c|c|c|}
\hline \multirow{2}{*}{$\begin{array}{l}\text { UNIDAD } \\
\text { MORFOLÓGICA }\end{array}$} & \multicolumn{3}{|c|}{$\beta$} & \multirow[b]{2}{*}{$\left(\mathbf{r}^{2}\right)$} \\
\hline & $\begin{array}{c}\mathbf{Q}_{\mathrm{ci}} \\
\left(\mathbf{m}^{3} \mathbf{s}^{-1}\right)\end{array}$ & $\begin{array}{l}\text { Retención sedimentos } \\
\left(\mathbf{m}^{3} \mathbf{a n ̃ o}^{-1}\right)\end{array}$ & $\begin{array}{c}\text { Extracciones } \\
\left(\mathbf{m}^{3} \mathbf{a n ̃ o}^{-1}\right)\end{array}$ & \\
\hline CAB & 0,64 & 0,85 & $-0,4$ & 0,99 \\
\hline BLA & 0,97 & - & $-0,23^{(1)}$ & 0,99 \\
\hline BCA & 0,88 & $-0,11^{(2)}$ & $-0,36$ & 0,98 \\
\hline $\mathrm{CA}$ & 0,98 & 0,122 & $-0,22$ & 0,99 \\
\hline
\end{tabular}

Nota: En todos los casos el p-valor es inferior a 0.05 menos en los casos (1) que es 0.062 y (2) que es 0.08 . 


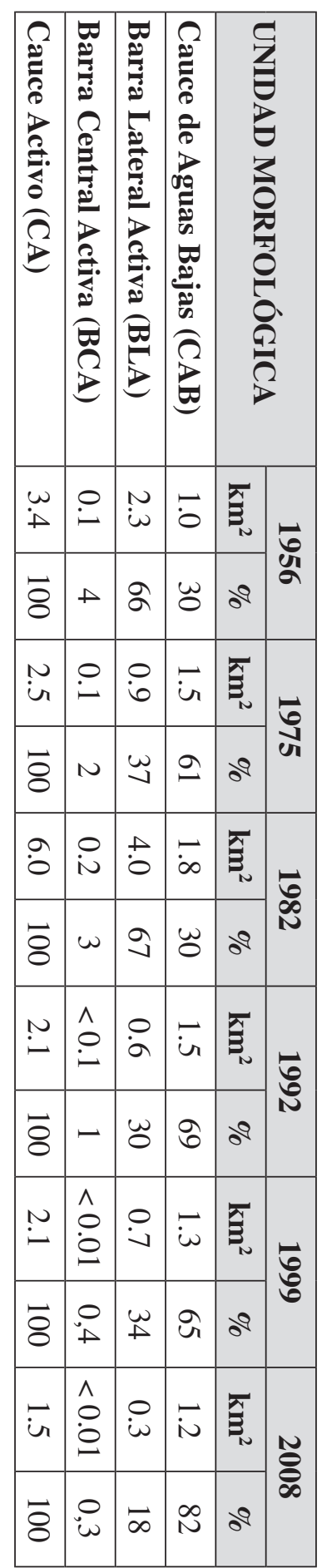

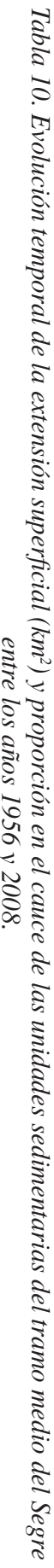




\section{Discusión}

El régimen hidrológico del Segre medio ha experimentado una serie de alteraciones desde finales de los años 1950, especialmente en relación con la magnitud y la frecuencia de las crecidas, y la variabilidad de sus caudales. La alteración del régimen fluvial debida a los embalses, junto con el déficit sedimentario causado por la retención en las presas y las extracciones de áridos, explican la baja intensidad de los procesos geomorfológicos actuales y la estabilidad que se observa en el cauce del río. Además de las grandes presas, la detracción de agua por parte del Canal d'Urgell afecta también de manera muy importante a la aportación anual de agua del río (los usos asociados al Canal superan los $450 \mathrm{hm}^{3}$ anuales), y por lo tanto a su caudal medio y a la variabilidad temporal, y con ello al régimen de crecidas (como mínimo a las ordinarias), que es el elemento central que controla la dinámica geomorfológica del cauce.

El cauce activo (Tabla 3), es la unidad morfológica que incluye el cauce de aguas bajas y las barras activas del río. La reducción observada en su extensión es producto de la pérdida de competencia de los caudales de crecida, así como de la falta de suministro de sedimentos desde la cuenca. Los resultados de la tabla 10 indican que desde 1975 el río presenta cada vez menos depósitos sedimentarios activos, algunos de los cuales incluso desaparecen colonizados por la vegetación de ribera u ocupados por cultivos. En esta situación de desequilibrio sedimentario, tan sólo la ocurrencia de eventos extremos, como la crecida de 1982, genera una nueva situación de inestabilidad, con un aumento considerable del cauce activo y de las unidades sedimentarias asociadas. Después de esta crecida, las unidades morfológicas vuelven a tener una extensión semejante a la de 1956. Esto se explica no solo por la elevada magnitud del evento sino también por la reactivación del sistema sedimentario, que libera material anteriormente retenido por la vegetación y por la coraza del lecho (diferencia entre el material superficial y el subyacente). Esta reactivación del sistema morfo-sedimentario no aportó grandes cantidades de material granular nuevo al tramo de estudio, sino que removilizó sedimentos que habían permanecido in situ (i.e. estables) durante las crecidas habituales. Las observaciones de campo en el tramo de estudio muestran evidencias de incisión de orden submétrico. En cualquier caso, y, según muestran las fotografías aéreas, después de 1982, el cauce entró rápidamente en un nuevo proceso de estabilización por la vegetación y sufrió numerosos impactos por la acción antrópica (extracciones de áridos y aumento de cultivos), alcanzando una situación de estabilidad similar a los anteriores a 1982. El ligero aumento en la frecuencia y la magnitud de las crecidas durante el periodo 1992-1999 no se ve reflejado en un gran incremento de la extensión del cauce activo. La entrada en funcionamiento del embalse de Rialb a finales de la década de 1990 incrementa la regulación fluvial y contribuye a una mayor retención de sedimentos, que hace aumentar la estabilidad del lecho hasta la situación de baja actividad sedimentaria que se observa en la actualidad. El impacto de las captaciones de agua del Canal d'Urgell sobre el régimen de caudales se hace manifiesto sobre todo entre abril y septiembre, alterando la magnitud de las crecidas habituales aguas abajo de la toma del canal. En algunos casos, las crecidas habituales quedan absorbidas por la toma de agua, alterando la energía y la frecuencia de las mismas. Las barras centrales son las unidades morfológicas que más se han visto afectadas por la pérdida de carga sólida. Cabe indicar que en el caso 
del tramo de estudio en el Segre aguas abajo de los embalses, existen varios afluentes que tienen una cuenca considerable (por ej. río Llobregós). Aun así, son tributarios de poca entidad hidrológica, hidráulica y geomorfológica, y no se les puede atribuir la capacidad suficiente para esperar de ellos una importante restauración del régimen sólido y líquido. Aguas abajo del embalse de Rialb el clima de la cuenca pasa de un clima mediterráneo de montaña (y alpino en la cabecera) a mediterráneo continental-seco. Este hecho hace que en muchos casos los ríos sean efímeros y su contribución hidrosedimentària se considera irrelevante.

Son numerosos los trabajos que analizan tramos fluviales afectados por actividades antrópicas. Por ejemplo, entre otros, Kondolf (1997), Liébault y Piégay (2002), Surian y Rinaldi (2003), Piégay et al. (2004), Batalla et al. (2006), Gregory (2006), Hooke (2006), Boix-Fayos et al. (2007), Surian et al. (2009), Magdaleno (2011) y Conesa y Pérez (2014) revisan y evalúan los efectos derivados de presas y minería de gravas, y presentan estrategias de restauración (Rinaldi et al., 2009). En este contexto, los principales efectos de la presencia de embalses (incisión, acorazamiento del lecho, erosión en los márgenes y contracción del cauce) y de la actividad extractiva (incisión, acorazamiento e inestabilidad lateral del cauce) están en concordancia con lo observado en nuestro trabajo. Según Surian y Rinaldi (2003), estos cambios acostumbran a producir una variación en el patrón morfológico del cauce, que por lo general pasa de trenzado a sinuoso, mostrando estrechamientos del cauce superiores al $50 \%$ en estos ambientes. El Segre es un claro ejemplo de cambios de sinuosidad (por ej. el SI del tramo \#2 pasa de 1.66 a 1.55 entre 1956 y 2008, siendo el mayor cambio de sinuosidad de los 4 sub-tramos analizados). Los efectos tienden a ser intensos en los primeros años de la construcción de cada embalse (i.e. entre 10 y 20 años) para luego prolongarse en el tiempo de manera más atenuada hasta llegar a un nuevo equilibrio, tal y como indican los trabajos clásicos de Petts (1984) y Williams y Wolman (1984).

En la cuenca del Ebro se han hecho también algunos estudios de este tipo, la mayor parte en el tramo del bajo Ebro (ver la revisión de esos trabajos en Batalla et al., 2014) y en algunos puntos del Pirineo. Por ejemplo, la regulación hidrológica junto con el dragado del tramo bajo del Ebro durante la última década (Batalla, 2003) ha causado cambios morfológicos con pérdidas de anchura del cauce activo del orden del 20 y el $25 \%$ (Vericat y Batalla, 2004; Batalla et al., 2006), algo menor que la observada en el Segre medio (i.e. $38 \%$ con el embalse de Oliana y $56 \%$ después de la construcción de la presa de Rialb). Ambos ríos se encuentran en el mencionado proceso de reequilibrio (Vericat et al., 2006), cuya magnitud y extensión en el tiempo dependen fundamentalmente del cambio en la magnitud y frecuencia de las crecidas y de la magnitud del déficit sedimentario en relación con la antigua aportación natural de la cuenca. En los casos del Ebro y del Segre, los caudales de baja frecuencia (i.e. cercanos al bankfull, responsables del mantenimiento morfo-sedimentario del cauce) son los caudales más afectados por la regulación hidrológica, hecho que explicaría la pérdida de actividad geomorfológica y el desarrollo de la vegetación de ribera madura. Cabe recordar también que, debido a la retención de sedimentos, las presas liberan agua limpia (hungry water según Kondolf, 1997). Esta situación conlleva un exceso de energía que el sistema utilizaba anteriormente en el transporte de sedimentos provenientes de la cuenca y que ahora disipa erosionando 
el cauce, fenómeno que disminuye aguas abajo, a medida que el lecho del río se va acorazando y va apareciendo la roca madre (Kondolf, 1997). En cuanto a la retención de sedimentos, los estudios llevados a cabo en ríos pirenaicos (Gómez-Villar y MartínezCastroviejo, 1991; García-Ruiz et al., 1997, 2010) muestran que los diques de retención pueden llegar a causar una incisión de hasta 3 m en 30 años. La incisión observada en la Ribera Salada, después de las extracciones entre 1987 y 2007, llega a los 3 m, dejando expuesta la roca madre en numerosos tramos. En el bajo Gállego, igualmente afectado por extracciones de áridos durante los años 1970 y 1980, y también por grandes presas aguas arriba, la incisión documentada llega a los 6 m (Martín-Vide et al., 2010). En todos estos ríos la incisión modificó el patrón del cauce pasando de trenzado a sinuoso, como consecuencia del desajuste entre la energía de los caudales y la carga sólida disponible en el cauce. La tabla 9 sintetiza numéricamente los principales cambios observados en el Segre y descritos por primera vez en relación a las alteraciones. La consecución de estos resultados ha sido posible gracias a la integración de diferentes métodos de diagnóstico hidrológico y sedimentario que a menudo se encuentran fragmentados o dispersos. Además, la metodología también integra trabajo de campo y un simple ejercicio de modelización para interaccionar los valores de caudal con la granulometría del cauce y así estimar la movilidad potencial del tramo del río Segre. Aunque existen diversos métodos para el estudio del estado hidro-sedimentario en sistemas fluviales (por ej. Richter et al., 1996; Raven et al., 1997; Mathews y Richter, 2007; Ollero et al., 2008; Alber y Piégay, 2011; Rinaldi et al., 2013; Lobera et al., 2015), la integración que se ha realizado en este artículo se considera como novedosa y de gran interés en el campo de la geomorfología fluvial.

\section{Conclusiones}

Este estudio propone una metodología, que a vista de los resultados, se considera adecuada para evaluar el estado morfo-sedimentario de tramos fluviales regulados por presas y/o impactados por extracciones de áridos. El análisis presenta dos conclusiones principales de acuerdo con las relaciones entre la magnitud-frecuencia de las crecidas y la reducción del área activa del cauce, así como entre la desaparición de unidades morfosedimentarias y la pérdida de disponibilidad de carga de fondo:

1. El régimen de caudales aguas abajo de la presa de Oliana es moderada, siendo el cambio más evidente el que afecta a la magnitud y frecuencia de las avenidas, fenómeno que se ha incrementado después de la construcción de la presa de Rialb. Dicha reducción, conjuntamente con el desequilibrio sedimentario estructural causado por las presas y local debido a las extracciones de áridos, explica la baja actividad sedimentaria actual del río. La intensidad de la actividad extractiva excedió ampliamente la carga media sedimentaria del río, hecho que, junto con los efectos de las presas, refuerza el déficit sedimentario y el desequilibrio morfodinámico del cauce actual (evidente a partir de las observaciones de acorazamiento y de incisión del lecho hasta la roca madre en algunos tramos).

2. La evolución morfológica del río muestra una tendencia a la estabilización por intrusión de vegetación de ribera, posterior al cierre del embalse de Oliana en 1959. Esta tendencia fue alterada en 1982 como consecuencia de una de las avenidas más 
importantes del siglo XX en la cuenca. El dinamismo fluvial aparente después del evento se ha reducido paulatinamente hasta la actualidad, pese a un ligero repunte de la actividad sedimentaria durante la década de 1990. La movilidad del cauce se ha reducido en su conjunto y la intrusión de la vegetación de ribera hace que el cauce de aguas bajas tienda a ocupar prácticamente la totalidad del cauce activo. Las principales unidades morfosedimentarias (barras laterales y centrales) han desaparecido.

En general, las crecidas controlan la expansión/contracción del cauce activo y el dinamismo de las unidades morfológicas y sedimentarias que lo conforman. Una menor disipación de energía provoca que el intercambio de materiales entre las capas superficial y subsuperficial del lecho sea menos frecuente y de menor intensidad (por ejemplo, tal y como indica el acorazamiento observado en el Segre), reduciendo a su vez la calidad del hábitat asociado y en su conjunto del ecosistema fluvial. Este trabajo pone de manifiesto, además, la necesidad de abordar los cambios en la dinámica fluvial a partir del análisis conjunto, hidrológico, hidráulico, sedimentario y de actividades antrópicas. Además, también se pone en evidencia la importancia de los datos de campo y ejercicios simples de modelización que permiten analizar la hidráulica del flujo relacionada con las características morfosedimentarias del cauce, y los posibles escenarios de movilidad de los sedimentos del lecho.

Los resultados aportan información para el diseño de programas de restauración hidrosedimentaria que incluyan prácticas tales como crecidas de mantenimiento que reactiven el cauce, y el bypass de sedimentos a través de las presas para reducir el desequilibrio energético y de masas, junto con inyección de gravas para minimizar la incisión y regenerar hábitats y unidades morfo-sedimentarias.

\section{Agradecimientos}

Este trabajo se ha realizado en el marco del Convenio entre la Agencia Catalana del Agua y el Centro Tecnológico Forestal de Catalunya para el estudio de la dinámica fluvial en las Cuencas Intercomunitarias del Segre-Ebro en Cataluña, y de los proyectos CGL2009-09770/BTE y Consolider Ingenio 2010 SCARCE CSD2009-00065 financiados por el Ministerio de Economía y Competitividad. El estudio se ha beneficiado de la metodología de análisis de datos desarrollada en el proyecto MORPHSED (CGL20123639), financiado por el Ministerio de Economía y Competitividad y Fondos Europeos FEDER. El segundo autor está contratado mediante el programa Ramón y Cajal (RYC2010-06264) del Programa Nacional de Contratación e Incorporación de Recursos Humanos de Investigación. El Grupo de Investigación de Dinámica Fluvial -RIUS es Grupo Consolidado reconocido por la Generalitat de Catalunya -2014 SGR 645.

\section{Referencias}

Alcázar, J. Palau, A. 2010. Establishing environmental flow regimes in a Mediterranean watershed based on a regional classification. Journal of Hydrology 388, 41-51.

Alber, A., Piégay, H. 2011. Spatial disaggregation and aggregation procedures for characterizing fluvial features at the network-scale: application to the Rhône basin (France). Geomorphology $125,343-60$. 
Baker, D.B., Richards, R.P., Loftus, T.T., Kramer, J.W. 2004. A new flashiness index: characteristics and applications to Midwestern rivers and streams. Journal of the American Water Resources Association 40, 503-522.

Balasch, J.C., Remacha, R., Escorihuela, B. 2006. El riu Segre a Lleida: La morfologia i els cabals., En El Riu Segre: Un Protagonista Anònim, X. Eritja (ed.), Pagés Editors, Lleida, pp. 13-32.

Batalla, R.J. 2003. Sediment deficit in rivers caused by dams and instream gravel mining. A review with examples from NE Spain. Cuaternario y Geomorfología 17, 79-91.

Batalla, R.J., Gómez, C.M., Kondolf, G.M. 2004. Reservoir-induced hydrological changes in the Ebro River basin (NE Spain). Journal of Hydrology 290, 117-136.

Batalla, R.J., Vericat, D. 2011. An appraisal of the contemporary sediment yield in the Ebro Basin. Journal of Soils and Sediments 11, 1070-1081.

Batalla, R.J., Vericat, D., Martínez, T. 2006. River-channel changes downstream from dams in the lower Ebro River. Zeitschrift für Geomorphologie, Suppl. B 143, 1-14.

Batalla, R.J., Vericat, D., Tena, A. 2014. The fluvial geomorphology of the lower Ebro (20022013): Bridging gaps between management and research. Cuadernos de Investigación Geográfica 40 (1), 29-51.

Beguería, S., López-Moreno, J.A., Gómez-Villar, A., Rubio, V., Lana-Renault, N., García-Ruiz, J.M. 2006. Fluvial adjustments to soil erosion and plant cover changes in the central Spanish Pyrenees. Geografiska Annaler 88 (3), 177-186.

Brune, G.M. 1953. Trap efficiency of reservoirs. Transactiions American Geophysical Union 34, 407-418.

Boix-Fayos, C., Barberá, G., López-Bermúdez, F., Castillo, V.M. 2007. Effects of check dams, reforestation and land-use changes on river channel morphology: Case study of the Rogativa catchment (Murcia, Spain). Geomorphology 91, 103-123.

Bunte, K., Abt, S.R. 2001. Sampling Surface and Subsurface Particle-size Distributions in Wadable Gravel- and Cobble-bed Streams for Analyses in Sediment Transport, Hydraulics, and Streambed Monitoring, General Technical Report RMRS. U.S. Department of Agriculture, Forest Service, Rocky Mountain Research Station, Fort Collins, 450 pp. Disponible en: http://www.stream.fs.fed.us (Fecha de acceso: 05/02/2014).

Campy, M., Macaire, J. 1989. Géologie des formations superficielles. Masson, Paris, 433 pp.

Chien, N. 1985. Changes in river regime after the construction of upstream reservoirs. Earth Surface Processes and Landforms 10, 143-159.

Church, M. 2006. Bed Material Transport and the Morphology of Alluvial River Channels. Annual Review of Earth and Planetary Sciences 34, 325-354.

Church, M.A., Mclean, D.G., Wolcott, J.F. 1987. River-bed gravels: sampling and analysis. En: Sediment Transport in Gravel-Bed Rivers. C.R. Thorne, J.C. Bathurst, R.D. Hey (ed.), John Wiley \& Sons, New York, pp. 43-88.

Clausen, B., Biggs, B.J.F. 2000. Flow variables for ecological studies in temperate streams: Groupings based on covariance. Journal of Hydrology 237, 184-197.

Conesa García, C., Pérez Cutillas, P. (2014). Alteraciones geomorfológicas recientes en los sistemas fluviales mediterráneos de la Península Ibérica. Síntomas y problemas de incisión en los cauces. Revista de Geografía Norte Grande 59, 25-44.

Communities European. 2003. Common Implementation Strategy for the Water Framework Directive (2000/60/EC), Guidance Document No 11. Office for Official Publications of the European Communities, Luxembourg, 86 pp. Disponible en: http://www.enorasis.eu/ uploads/files/Water\%20Governance/10.Guidancedoc11_PlanningProcess.pdf (Fecha de acceso: 05/02/2014).

Copp, G.H. 1989. The habitat diversity and fish reproductive function of floodplain ecosystems. Environmental Biology of Fishes 26, 1-27. 
Tuset et al.

Crozzoli, L., Batalla, R.J. 2003. Aplicación de la fotografía al análisis granulométrico de ríos con lecho de gravas. Cuaternario y Geomorfología 17, 29-39.

Díaz, V., Mongil, J., Navarro, J. 2014. Propuesta de una nueva metodología para determinar la efectividad de los diques en la retención de sedimentos. Cuadernos de Investigación Geográfica 40 (2), 169-190.

DMAH. 2004. Classificació dels usos del sòl a Catalunya 2002. Disponible en: http://www.creaf. uab.es/miramon/CAT/MMZ.htm (Fecha de acceso: 20/01/2014).

Egiazaroff, I. V. 1965. Calculation of nonuniform sediment concentrations. Journal of the Hydraulics Division, ASCE 91, 225-248.

Fenner, P., Brady, W.W., Patton, D.R. 1985. Effects of regulated water flows on regeneration of Fremont cottonwood. Journal of Range Management 38, 135-138.

García-Ruiz, J.M., Alatorre, L.C., Gómez-Villar, A., Beguería, S. 2010. Upstream and downstream effects of check dams in braided rivers, Central Pyrenees. En Check Dams, Morphological Adjustments and Erosion Control in Torrential Streams, C. Consesa y M. Aristide (ed.), Nova Science Publishers, pp. 307-322.

García-Ruiz, J.M., White, S.M., Lasanta, T., Marti, C., Gonzalez, C., Errea, M.P., Valero, B., Ortigosa, L. 1997. Assessing the effects of land-use changes on sediment yield and channel dynamics in the central Spanish Pyrenees. En Human Impact on Erosion and Sedimentation, D.E. Walling y J. Probst (ed.), IAHS Publication 245, 151-158.

García-Ruiz, J.M. (2010). The effects of land uses on soil erosion in Spain: A review. Catena, 81, $1-11$.

Gómez-Villar, A., Martínez-Castroviejo, R. 1991. Channel degradation as a response to erosion control works: a case study. En Soil Erosion Studies in Spain, M. Sala y J.L. Rubio (ed.), Geoforma Edicions, Logroño, pp. 109-122.

Graham, D.J., Reid, I., Rice, S.P. 2005. Automated sizing of coarse grained sediments: Imageprocessing procedures. Mathematical Geology 37(1), 1-28.

Gregory, K.J. 2006. The human role in changing river channels. Geomorphology 79, 172-191.

Growns, J., Marsh, N. 2000. Characterisation of Flow in Regulated and Unregulated Streams in Eastern Australia, Technical Report 3/2000, Cooperative Research Centre for Freshwater Ecology, Canberra, 70 pp. Disponible en: http://ewater.com.au/ (Fecha de acceso: 05/02/2014).

Hooke, J.M. 2006. Human impacts on fluvial systems in the Mediterranean region. Geomorphology 79 (3-4), 311-335.

Kondolf, G. 1994a. Geomorphic and environmental effects of instream gravel mining. Landscape and Urban Planning 28, 225-243.

Kondolf, G.M. 1994b. Environmental planning in regulation and management of instream gravel mining in California. Landscape and Urban Planning 29, 185-199.

Kondolf, G.M. 1997. Hungry water: Effects of dams and gravel mining on river channels. Environmental management 21, 533-551.

Liébault, F., Piégay, H., 2002. Causes of 20th century channel narrowing in mountain and piedmont rivers of Southeastern France. Earth Surface and Landforms 27, 425-444.

Lobera, G., Besné, P., Vericat, D., López-Tarazón, J., Tena, A., Aristi, I., Díez, J.R., Ibisate, A., Larrañaga, A., Elosegi, A., Batalla, R.J. 2015. Geomorphic status of regulated rivers in the Iberian Peninsula. Science of The Total Environment 508, 101-114.

López-Vicente, M., Lana-Renault, N., García-Ruíz, J.M., Navas, A. 2011. Assessing the potential effect of different land cover management practices on sediment yield from an abandoned farmland catchment in the Spanish Pyrenees. Journal of Soils and Sediments, 11, 8, 14401455.

LUEL 2005. Digital Gravelometer. Disponible en: http://www.sedimetrics.com/ (Fecha de acceso: 04/03/2015). 
Magdaleno, F. 2011. Evolución hidrogeomorfológica del sector central del río Ebro a lo largo del siglo XX: implicaciones ecológicas para su restauración. Universidad Politécnica de Madrid, Tesis Doctoral, $91 \mathrm{pp}$.

Manning, R. 1891. On the flow of water in open channels and pipes. Transactions of the Institution of Civil Engineers of Ireland 20, 161-207.

Martínez-Santa, C.M., Fernández-Yuste, J.A. 2006. Índices de Alteración Hidrológica en Ecosistemas Fluviales. Ministerio de Medio Ambiente, Madrid, 178 pp.

Martín-Vide, J.P. 2002. Ingeniería de ríos. Edicions UPC, Barcelona, 404 pp.

Martín-Vide, J.P., Ferrer-Boix, C., Ollero, A. 2010. Incision due to gravel mining: Modeling a case study from the Gallego River, Spain. Geomorphology 117, 261-271.

Mathews, R., Richter, B.D. 2007. Application of the indicators of hydrologic alteration software in environmental flow setting. J Am Water Resour Assoc 43,1400-1413.

Molina-Navarro, E., Martínez-Pérez, S., Sastre-Merlin, A., Bienes-Allas, R. 2014. Taking advantage of a new hydraulic infrastructure to study the sediment yield in a small basin of central Spain. Cuadernos de Investigación Geográfica 40 (1), 29-51.

Ollero, A., Ballarín, D., Díaz, E., Mora, D., Sánchez, M., Acín, V., et al. 2008. IHG: Un índice para la valoración hidrogeomorfológica de sistemas fluviales. Limnética 27,171-187.

OWRRI (OSU) 1995a. Gravel disturbance impacts on salmon habitat and stream health. Vol 1: Summary Report. Oregon Division of State Lands, Salem, 52 pp. Disponible en: http:// andrewsforest.oregonstate.edu/pubs/pdf/pub2207.pdf (Fecha de acceso: 03/02/2014)

OWRRI (OSU). 1995b. Gravel disturbance impacts on salmon habitat and stream health. Vol 2: Technical background report. Oregon Division of State Lands, Salem. 228 pp. Disponible en: https://ir.library.oregonstate.edu/xmlui/handle/1956/54823 (Fecha de acceso: 03/02/2014).

Petts, G.E. 1984. Impounded rivers: perspectives for ecological management. John Wiley \& Sons, New York, 326 pp.

Piégay, H., Alber, A., Slater, L., Bourdin, L., 2009. Census and typology of braided rivers in the French Alps. Aquatic Sciences 71, 371-388.

Piégay, H., Walling, D.E., Landon, N., Quinping, H., Liébault, F., Petiot, R. 2004. Contemporary changes in sediment yield in a mountain basin due to afforestation (the upper Drôme in France). Catena 55, 183-212.

Poff, N.L., Allan, J.D., Bain, M.B., Karr, J.R., Prestegaard, K.L., Richter, B.D., Sparks, R.E., Stromberg, J.C. 1997. The Natural Flow Regime: A paradigm for river conservation and restoration N. BioScience 47, 769-784.

Pringle, C.M. 1997. Exploring how disturbance is transmitted upstream: Going against the flow. Journal of the North American Benthological Society 16, 425-438.

Puckridge, J.T., Sheldon, F., Walker, K.F., Boulton, A.J. 1998. Flow variability and the ecology of large rivers. Marine and Freshwater Research 49, 55-72.

Puigdefàbregas, C. 1984. Efectes geomorfològics dels aiguats del novembre de 1982. Generalitat de Catalunya, Barcelona, 236 pp.

Raven, P.J., Fox, P.J.A., Everard, M., Holmes, N.T.H., Dawson, F.H. 1997. River habitat survey: a new system for classifying rivers according to their habitat quality. En Freshwater quality: defining the indefinable?, P.J. Boon, D.L. (ed.), The Stationery Office, Edinburgh, pp. 215234.

Rice, S., Church, M. 1998. Grain size along two gravel-bed rivers: Statistical variation, spatial pattern and sedimentary links. Earth Surface Processes and Landforms 23, 345-363.

Richter, B.D., Baumgartner, J.V., Powell, J., Braun, D.P. 1996. A method for assessing hydrologic alteration within ecosystems. Conservation Biology 10, 1163-1174.

Rinaldi, M., 2003. Recent channel adjustments in alluvial rivers of Tuscany, central Italy. Earth Surface Process. and Landforms 28, 587-608. 
Tuset et al.

Rinaldi, M., Simoncini, C., Piegay, H. 2009. Scientific design strategy for promoting sustainable sediment management: the case of the Magra River (Central Northern Italy). River Research and Applications 25 (5), 607-625.

Rinaldi, M., Surian, N., Comiti, F., Bussettini, M. 2013. A method for the assessment and analysis of the hydromorphological condition of Italian streams: the Morphological Quality Index (MQI). Geomorphology 180-181, 96-108.

Rivier, B., Seguier, J. 1985. Physical and biological effects of gravel extraction in river beds. En Habitat Modification and Freshwater Fisheries. En J.S. Alabaster (ed.), Butterworths, London, pp. 131-146.

Rundquist L.A. 1980. Effects of gravel removal on river hydrology and hydraulics. En Gravel Removal Studies in Arctic and Subarctic Floodplain in Alaska - Technical Report, W.C. Consultants (ed.), U.S. Fish Wildl. Serv., pp. 67-140. Disponible en: http://pubs.aina. ucalgary.ca/gran/5989.pdf (Fecha de acceso: 03/02/2014).

Sanchis Ibor, C, Segura Beltrán, F.S., 2014. Spatial variability of channel changes in a Mediterranean ephemeral stream in the last six decades (1946-2006). Cuadernos de Investigación Geográfica 40 (1), 89-118.

Schumm, S.A. 1963. Sinuosity of alluvial rivers on the great plains. Geological Society of America Bulletin 74, 1089-1099.

Schumm, S.A. 1977. The Fluvial system. John Wiley, New York, 338 pp.

Strickler A., 1923. Beiträge zur Frage der Geschwindigkeitsformel und der Rauhigkeitszahlen fur Ströme, Kanäle und Geschlossene Leitungen. Berna. Switzerland, Mitt. Eidgenoassischen Amtes Wasserwirtschaft, n. 16.

Surian, N. 1999. Channel changes due to river regulation: the case of the Piave river, Italy. Earth Surface Processes and Landforms 24, 1135-1151.

Surian, N., Rinaldi, M. 2003. Morphological response to river engineering and management in alluvial channels in Italy. Geomorphology 50, 307-326.

Sutherland, A.J. 1992. Hiding functions to predict self armouring. En International Grain Sorting Seminar. Mit. Der Versuchsanstalt Für Wasserbau Hydrologie Und Glaziologie. ETH, Zurich, 273-298.

USACE (U.S.A.C.O.E.) 2010. HEC-RAS, Hydrologic Engineering Centers River Analysis System, Usuer's Manual, Version 4.1. U.S. Army Corps of Engineers, Davis, 790 p. Disponible en: http://www.hec.usace.army.mil/software/hec-ras/documentation/HEC-RAS_4.1_Users_ Manual.pdf (Fecha de acceso: 05/02/2014).

Vericat, D., Batalla, R.J. 2004. Efectos de las presas en la dinámica fluvial del curso bajo del río Ebro. Cuaternario y Geomorfología 18, 37-50.

Vericat, D., Batalla, R.J. 2010. Sediment transport from continuous monitoring in a perennial Mediterranean stream. Catena 82, 77-86.

Vericat, D., García, C., Batalla, R.J. 2006. Variaciones temporales y espaciales en la granulometría del tramo bajo del Ebro. Cuaternario y geomorfología 20, 47-60.

Villarroya, C., Xuclá, R.S. 2003. La delimitación del dominio público hidráulico y de sus zonas inundables: el proyecto Linde. Ministerio de Medio Ambiente, Madrid, 93 pp.

White, R.W., Day, T.J. 1982. Transport of graded gravel bed material. En Gravel-Bed Rivers, J.C. Hey, J.C. Bathurst y C.R. Thorne (eds.), John Wiley, New York, 181-223.

Williams, G.P., Wolman, M.G. 1984. Downstream effects of dams on alluvial rivers. Geological Survey Professional Paper 1286. United States Government Printing Office, Washington, 94 pp. Disponible en: http://pubs.usgs.gov/pp/1286/report.pdf (Fecha de acceso: 05/02/2014).

Wolman, M.G. 1954. A method of sampling coarse bed-material. American Geophysical Union Transactions 35, 951-956. 


\section{Notaciones}

\#1 Correspondiente al Sub-Tramo 1

\#2 Correspondiente al Sub-Tramo 2

\#3 Correspondiente al Sub-Tramo 3

\#4 Correspondiente al Sub-Tramo 4

$\mathrm{CAB} \quad$ Extensión del Cauce de Aguas Bajas (en $\mathrm{km}^{2}$ )

$\mathrm{a}_{\mathrm{i}} \quad$ Valor resultante que toma cada índice de alteración parcial

$\overline{\mathrm{Q}_{\mathrm{C}}} \quad$ Media de los máximos caudales diarios anuales $\left(\mathrm{en}^{3} \mathrm{~s}^{-1}\right)$

$\overline{\mathrm{Q}_{\mathrm{C} 1}} \quad$ Media de los caudales máximos instantáneos anuales (en $\mathrm{m}^{3} \mathrm{~s}^{-1}$ )

B Coeficientes no estandarizados, representando las contribuciones independientes de cada variable independiente a la predicción de la variable dependiente

BCA Barra Central Activa (en $\mathrm{km}^{2}$ )

BCV Barra Central Vegetada (en $\left.\mathrm{km}^{2}\right)$

BLA Barra Lateral Activa $\left(\mathrm{en} \mathrm{km}^{2}\right)$

CA Cauce Activo (en $\left.\mathrm{km}^{2}\right)$

CHE Confederación Hidrográfica del Ebro

CUL Cultivos $\left(\mathrm{en}^{2} \mathrm{~km}^{2}\right.$

$\mathrm{CV}_{\mathrm{QC}} \quad$ Coeficiente de variación de la serie de máximos caudales medios diarios anuales

$\mathrm{CV}_{\mathrm{Q}} \quad$ Coeficiente de variación de la serie de avenidas habituales

d Calado (en m)

$\mathrm{D}_{16-\mathrm{s}} \quad$ Percentil 16 de la distribución granulométrica del sedimento superficial (en m)

$\mathrm{D}_{50-\mathrm{s}} \quad$ Percentil 50 de la distribución granulométrica del sedimento superficial (en m)

$\mathrm{D}_{50-\text { ss }} \quad$ Percentil 50 de la distribución granulométrica del sedimento sub-superficial (en m)

$\mathrm{D}_{60-\mathrm{s}} \quad$ Percentil 60 de la distribución granulométrica del sedimento superficial (en m)

$\mathrm{D}_{84-\mathrm{s}} \quad$ Percentil 84 de la distribución granulométrica del sedimento superficial (en m)

$\mathrm{D}_{90 \text {-s }} \quad$ Percentil 90 de la distribución granulométrica del sedimento superficial (en m)

$\mathrm{D}_{\mathrm{i}} \quad$ Diámetro de la partícula del percentil (i) correspondiente de la distribución granulométrica superficial (en m)

$\mathrm{D}_{\mathrm{u}} \quad$ Tamaño representativo de la partícula superficial basado en el trabajo de White y Day (1982) formulado, $\mathrm{D}_{\mathrm{u}-\mathrm{a}}=1,6 . \mathrm{D}_{50-\mathrm{s}}\left(\mathrm{D}_{84-\mathrm{s}} / \mathrm{D}_{16-\mathrm{s}}\right)-0,28$ (en m)

$\mathrm{D}_{\mathrm{x}} \quad$ Percentil de la distribución granulométrica del sedimento superficial de referencia (en m)

EMQ Error Medio Cuadrático (en m)

F Distribución F de Fisher-Snedecor

g Constante gravitacional (en $\mathrm{m} \mathrm{s}^{-2}$ )

GCP Puntos de control en el terreno

HEC-RAS Hydrologic Engineering Centers River Analysis System (Software)

Ia Índice de acorazamiento (adimensional), se define como el cociente entre $\mathrm{D}_{50-\mathrm{s}}$ y $\mathrm{D}_{50 \text {-ss }}$

IAG Índice de Alteración Global (adimensional)

IAH Índices de Alteración Hidrológica, formados por los $\mathrm{IMF}_{\mathrm{Cm}-\mathrm{Bank}-\mathrm{Ch}}, \mathrm{IV}_{\mathrm{Cm}-\mathrm{Ch}}, \mathrm{IE}_{\mathrm{Cd}}$ e $\mathrm{ID}_{\mathrm{Cd}}$ (adimensional)

$\mathrm{ID}_{\mathrm{Cd}} \quad$ Índice de Duración de Crecidas

$\mathrm{IE}_{\mathrm{Cd}} \quad$ Índice de Estacionalidad de Crecidas 
IDF Índice de Dinámica Fluvial (adimensional)

$\mathrm{IMF}_{\mathrm{Cm}} \quad$ Índice de Crecidas Máximas

$\mathrm{IMF}_{\text {Bank }} \quad$ Índice de Caudal Bankfull

$\mathrm{IMF}_{\mathrm{Ch}} \quad$ Índice de Crecidas Habituales

IR Índice de Regulación (adimensional; Batalla et al., 2004)

$\mathrm{IV}_{\mathrm{Cm}} \quad$ Índice de Variabilidad de Crecidas máximas diarias anuales

$\mathrm{IV}_{\mathrm{Ch}} \quad$ Índice de Variabilidad de Crecidas Habituales

$\mathrm{m} \quad$ Número de índices que evalúan cada aspecto del régimen de caudales

$\mathrm{n} \quad$ Coeficiente de rugosidad de Manning

$\mathrm{n}_{\mathrm{a}} \quad$ Número de años completos de una serie (en años)

$\mathrm{Q}_{5} \quad$ Caudal máximo ordinario o caudal de crecida habitual $\left(\mathrm{en}^{3} \mathrm{~s}^{-1}\right)$

$\mathrm{Q}_{10} \quad$ Percentil 10 de los caudales medios diarios $\left(\mathrm{en} \mathrm{m}^{3} \mathrm{~s}^{-1}\right)$

$\mathrm{Q}_{50} \quad$ La mediana de la serie de caudales medios diarios $\left(\mathrm{en}^{3} \mathrm{~s}^{-1}\right)$

$\mathrm{Q}_{90} \quad$ Percentil 90 de los caudales medios diarios $\left(\mathrm{en}^{3} \mathrm{~s}^{-1}\right)$

$\mathrm{Q}_{\text {Bank }} \quad$ Caudal bankfull $\left(\mathrm{en}^{3} \mathrm{~s}^{-1}\right)$

$\mathrm{Q}_{c} \quad$ Caudal medio diario máximo del año $\left(\mathrm{en} \mathrm{m}^{3} \mathrm{~s}^{-1}\right)$

$\mathrm{Q}_{\mathrm{c}}^{*} \quad$ Caudal critico $\left(\mathrm{en} \mathrm{m}^{3} \mathrm{~s}^{-1}\right)$

$\mathrm{Q}_{\mathrm{ci}} \quad$ Caudal instantáneo máximo del año $\left(\mathrm{en}^{3} \mathrm{~s}^{-1}\right)$

$\mathrm{Q}_{\mathrm{Esp}} \quad$ Caudal específico $\left(\mathrm{en}^{3} \mathrm{~s}^{-1}\right)$

$\mathrm{Q}_{\mathrm{n}} \quad$ Caudal diario medio $\left(\mathrm{en}^{3} \mathrm{~s}^{-1}\right)$

$\mathrm{R}_{\mathrm{m}} \quad$ Rango medio anual de dispersión entre caudales diarios

RMC Régimen modificado de caudales

$\mathrm{RMC}_{\mathrm{Hb}} \quad$ Régimen modificado de los caudales habituales

$\mathrm{RMC}_{\mathrm{Cd}} \quad$ Régimen modificado de crecidas

RNC Régimen natural de caudales

$\mathrm{S} \quad$ Pendiente $\left(\mathrm{en} \mathrm{m} \mathrm{m}^{-1}\right)$

$\mathrm{S}_{\mathrm{RMC}} \quad$ Superficie definida por el polígono de RMC

$\mathrm{S}_{\mathrm{RNC}} \quad$ Superficie definida por el polígono de RNC

$\mathrm{T}_{2}$

$\mathrm{T}_{5}$

Crecidas de 2 años de período de retorno (en años)

Crecidas de 5 años de período de retorno (en años)

$\begin{array}{ll}\mathrm{T}_{10} & \text { Crecidas de } 10 \text { años de período de retorno (en años) } \\ \mathrm{T}_{50} & \text { Crecidas de } 50 \text { años de período de retorno (en años) }\end{array}$

$\mathrm{T}_{\mathrm{x}} \quad$ Periodo de retorno $(x)$ respecto a un caudal determinado (en años)

$\mathrm{X} \quad$ Símbolo representativo de las variables independientes de la regresión múltiple

Y Símbolo representativo de las variables independientes de la regresión múltiple

$\beta \quad$ Coeficientes de regresión parciales estandarizados, definen la ecuación de regresión cuando ésta se obtiene tras estandarizar las variables originales, es decir, tras convertir las puntuaciones directas en típicas

$\varepsilon_{\mathrm{i}-\mathrm{s}} \quad$ Función de protección atribuida a una partícula $\mathrm{D}_{\mathrm{i}}$ (hiding)

@ Densidad del agua (en $\mathrm{kg} \mathrm{m}^{-3}$ )

$\varrho_{s} \quad$ Densidad específica del sedimento (en $\left.\mathrm{kg} \mathrm{m}^{-3}\right)$

$\sigma \quad$ Desviación típica de una muestra

$\tau \quad$ Tensión de corte que ejerce el agua $\left(\mathrm{en}^{\mathrm{N} \mathrm{m}} \mathrm{m}^{-2}\right)$

$\tau^{*} \quad$ Tensión crítica de Shields (adimensional)

$\tau_{\mathrm{c}-\mathrm{Di}} \quad$ Tensión de corte crítica para la movilización de una partícula de material superficial de tamaño $\mathrm{D}_{\mathrm{i}}\left(\mathrm{en} \mathrm{N} \mathrm{m}^{-2}\right)$ 